\title{
A Novel Qualification Procedure to Manufacture and Repair Aerospace Parts with Electron Beam Melting
}

\author{
L. Portolés ${ }^{b, *}$, O. Jordáb ${ }^{\text {, L. Jordáb }}$, A. Uriondo ${ }^{a, *}$, M. Esperon-Miguez ${ }^{a}$, \\ S. Perinpanayagam ${ }^{\mathrm{a}}$ \\ ${ }^{a} I V H M$-Boeing Centre, Cranfield University, Bedforshire MK43 OAL, United Kingdom \\ ${ }^{b}$ AIMME-Instituto Tecnológico Metalmecánico, Parque Tecnológico, Avd.Leonardo Da \\ Vinci, 38, 46980 Valencia, Spain
}

\begin{abstract}
This paper is focused on Qualification Procedures for metal parts manufactured using new Additive Manufacturing (AM) techniques in the aerospace industry. The main aim is to understand the interaction between these technologies and the stringent regulatory framework of this industry in order to develop correct Quality Assurance and Quality Control procedures in accordance with the certification process for the technology and spare parts. These include all the testing and validation necessary to implement them, as well as to maintain their capability throughout their life-cycle, specific procedures to manufacture or repair parts, work-flows and records amongst others. An entire novel Qualification Procedure for Electron Beam Melting (EBM) to reproduce and repair an aerospace part has been developed and it is presented in this paper. These will be part of the future Quality Assurance and Quality Management systems of those aerospace companies that implement AM in their supply chain.

Keywords: Quality Assurance, Qualification, Quality, Electron Beam

Melting, Aerospace Industry, Certification
\end{abstract}

\footnotetext{
RepAIR.

* Corresponding authors

Email addresses: lportoles@aimme.es (L. Portolés), a.uriondo@cranfield.ac.uk (A. Uriondo)
} 


\section{Contents}

1 Introduction $\quad 2$

2 Qualification Procedure for EBM and SLM 4

2.1 Process specification development . . . . . . . . . . . . 5

$5 \quad 2.2$ Identification of key variables and parameters . . . . . . . . . 7

2.3 Influence of various critical parameters and variables . . . . . . 8

2.4 Allowable range . . . . . . . . . . . . . . 8

3 Use case $\quad 8$

3.1 Qualification Procedure: building platform . . . . . . . . . 10

3.2 Qualification Procedure studies ............. 11

3.2.1 Study 1-Validation of recycled powder . . . . . . . . 11

3.2.2 Study 2-Correlation between powder and bulk material in terms of chemical composition 1

3.2.3 Study 3-Bulk material characterisation into the key factors 12

3.2.4 Studies 4 and 5-Post processes . . . . . . . . . . 14

3.2.5 Study 6-Demo part validation . . . . . . . . . . . . 14

3.2.6 Study 7-Process reproducibility . . . . . . . . . . 16

3.2.7 Study 8-Material interface analysis . . . . . . . . . . . 17

3.2.8 Study 9- Machining the part and surface preparation . . . 17

4 Results 18

5 Conclusions $\quad 22$

\section{Introduction}

There is broad consensus on the potential applications of Additive Manufacturing (AM) technologies for repairing and manufacturing parts in the aerospace industry. There are many studies on the capability of this technology for de25 signing parts in this industry [1-3]; repairing and manufacturing parts for turbo engines [4]; in the spare part supply chain in MRO processes [5-7]; amongst others.

The main characteristics that make this technology attractive for this industry include optimal raw material usage, reduced raw material stock size, fewer 
machine operations, reduced hard tooling requirements and reduced lead times when compared to other conventional manufacturing processes like forging, casting or machining. The buy-to-fly ratio is a measure of the material efficiency in terms of the amount of raw material needed for manufacturing the final part. In contrast with traditional machining methods, which have buy-to-fly ratios between 5 and 20 [8], AM can achieve values close to one [9]. Groneck [10] highlights some advantages in terms of cost and cycle-time savings by switching from multi-piece built-up assembly to a single-piece.

In the aerospace sector, AM processes must be developed to meet the industry's stringent requirements and to ensure that products can achieve the robust 40 performance levels established by traditional manufacturing methods, as well as, comply with the regulation framework.

Requirements for commercial aircrafts parts are mainly based on the regulations of the European Aviation Safety Agency (EASA) and regulations of the Federal Aviation Administration (FAA). These regulations are extensive and detailed, but the single most pertinent regulations in the context of AM can be found in CS-25, Book 1, Subpart D, Subsections CS 25.603 and CS 25.605 [11].

1. CS 25.603 Materials. The suitability and durability of materials used for parts, the failure of which could adversely affect safety, must:

- be established on the basis of experience or tests;

- conform to approved specifications, that ensure their having the strength and other properties assumed in the design data (See AMC 25.603(b)); and

- take into account the effects of environmental conditions, such as temperature and humidity.

\section{CS 25.605 Fabrication methods.}

- Methods of fabrication used must produce a consistently sound structure. If a fabrication process (such as gluing, spot welding, or heat treating) requires close control to reach this objective, the process must be performed under an approved process specification; and

- each new aircraft fabrication method must be substantiated by a test programme 
With the lack of technology maturity in terms of design, qualification, process specifications and standardisation, it is difficult for the aerospace industry to develop a single specification and associated database for AM of a given alloy.

${ }_{65}$ The AM process itself is not sufficient to produce an airworthy component. Heat treatments, such as stress relief or Hot Isostatic Pressing (HIP), are required to improve structural properties $[12,13]$. Machining the surface is required to reduce roughness, increase dimensional accuracy, and to prevent the initiation of surface cracks [14].Therefore, process specifications for each aircraft component should be defined from the beginning.

The Qualification Procedure (QP) is an important issue for implementing AM in the aerospace market. This can be defined as a methodology by which all critical parameters and their allowance ranges are identified, and the repeatability of the process is also guaranteed. In other words, the QP is the method used for the assessment of all the variables/factors suitable to influence both technical requirements of the final part and process reproducibility. The QP requires the assessment and control of key raw materials, consumables, and process parameters; the development of a fixed practice for each AM component; the verification of each fixed practice via NDI and destructive testing; and part-specific acceptance testing (both NDI and destructive testing) to ensure the integrity of parts.

This paper presents a novel QP for EBM and SLM to reach the reproducibility of the results. This result would be the basis for future QA/QC procedures.

\section{Qualification Procedure for EBM and SLM}

This novel Qualification Procedure (QP) presents a methodology to assess all the variables/factors that can influence both, technical requirements of the final part and process reproducibility. It takes into account potential dependencies between different process variables in the specification procedure. Figure 1 outlines all QP steps. 


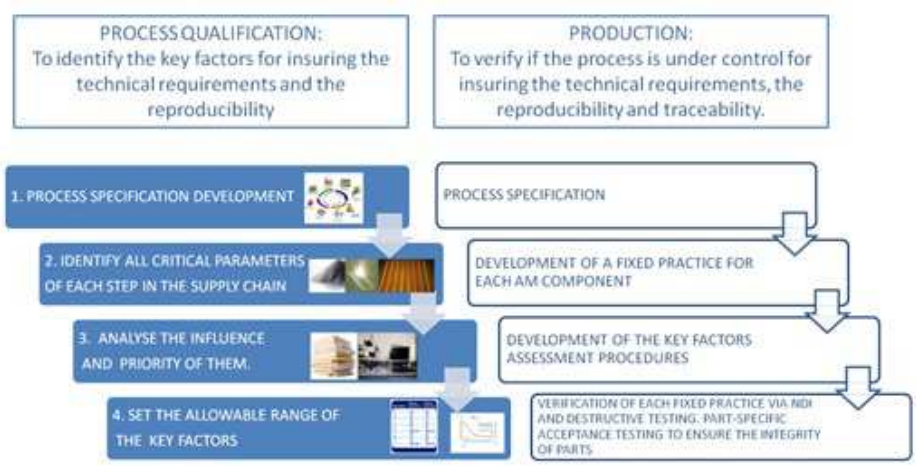

Figure 1: General description of the Qualification Procedure

90

\subsection{Process specification development}

In this step, a process specification has to be developed for manufacturing/repairing each aircraft' component. As part of the process specification, the $\mathrm{AM}$ process and post-processes must be established based on technical requirements (see Table 1).

Therefore, the process specification for manufacturing or repairing a component should be established based on all the information previously gathered. Each process specification should include at least:

- Manufacturing technologies. All the manufacturing/repairing techniques used for achieving the final part.

- Data of raw material. The specifications for the powder, the powder handling guidelines, the recyclability of the powder, the ageing allowed for the powder, and the powder blend procedure.

- AM process plan. It includes all geometries to be built per cycle. Each cycle is constituted by an individual build platform. Depending on the processes' specifications, it can be necessary to build different test samples per cycle to check the mechanical properties, chemical composition and microstructure. The location of the parts in the building platform and the manufacturing orientation must be considered as well.

- Post-processing plan. It provides relevant information about any post- 
Table 1: Technical requirements and aspects related with AM

\section{Technical Requirements}

Material(s) Specification(s)

Geometry

Operating Conditions

Faiulure Modes

Traceability
Aspect

Material standards establish the proper chemical, composition, and some conditions for purchasing, storing, handling or processing the material. They usually reference other standards related to testing methods to assess mechanical properties. Special attention has been given to the standards published by the ASTM F-42 and TC-261 standardisation groups.

Apart from 3D models, dimensional, geometric and surface tolerances must be specified. In order to have better fatigue behaviour, the roughness of the surface is crucial. The surface has to be machined, which means that all the extra material needed must be in the $3 \mathrm{D}$ solid model file.

It provides information related to its use, such as loads, environmental conditions, temperature range, pressure range, humidity range, and interactions with other parts or systems amongst others.

It provides information about the possible failure modes such as type, frequency, location, and mean repair/replace time. This is often captured in FMECAs.

It provides information and documentation about the process-history. It includes information about raw materials, consumables, subprocesses, personnel, NDT testing, machinery and technologies, and post-processes amongst others. 


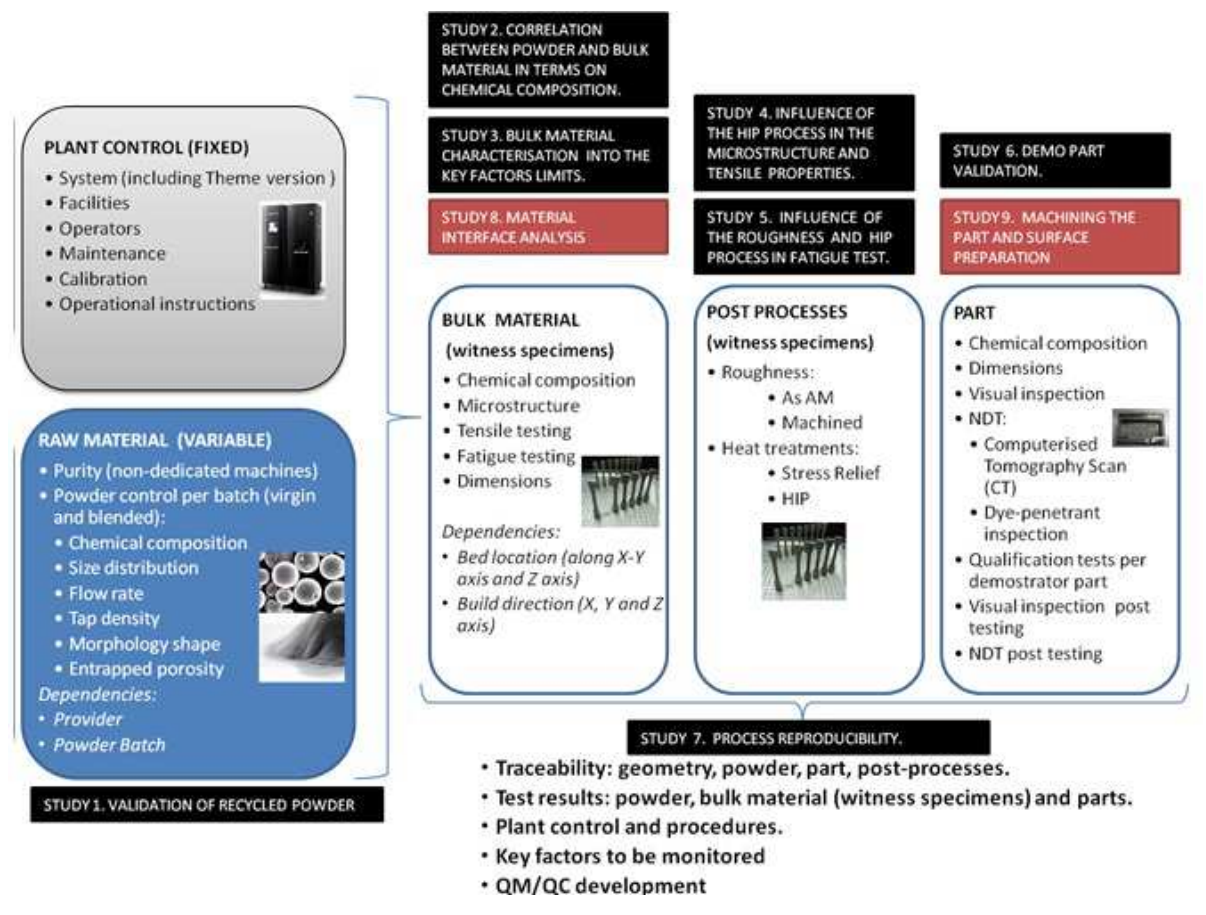

Figure 2: AM process parameter classification

- Assessment plan. It establishes a set of studies to conduct the assessment of the part and the process via Non-Destructive Testing (NDT) and destructive tests.

- Process reproducibility description. It establishes the required number of butches and samples to be produced and tested in order to guarantee the established requirements.

\subsection{Identification of key variables and parameters}

During the manufacturing or repairing process it is important to determinate the potential dependencies between all involved variables and parameters. It is also important to take into consideration variables from other manufacturing or repairing processes that directly affect the final part. These variables and parameters can be classified into various groups depending on their nature. Figure 2 shows this group classification with its relevant aspects. 


\subsection{Influence of various critical parameters and variables}

Taking into account results from various EBM/SLM applications [15-19], the following QP studies (see Table 2) have been used to characterise the effect of various critical parameters and variables during the manufacturing process.

Figure 2 correlates these studies with the previous parameter classification. Parts can be repaired using AM by removing the material of the damaged area and reconstructing the part using the undamaged remaining material as a base. Some additional studies would be considered in a repair process. This occurs due to the "hybrid" nature of the final part. When a part has been repaired adding material on a substrate, both can be different in terms of microstructure and chemical compositions. The "transition zone" between both materials will have its own characteristics. For these reasons, studies 7 and 8 must be added into the QP for a repair operation.

\subsection{Allowable range}

Finally, once key factors and their allowed ranges have been fixed, it is possible to determine if the manufacturing process has been successful. Allowed range-factors to make the relevant decisions to achieve the desired quality level. The evaluation of key factors must be implemented in the quality control procedures.

\section{Use case}

The selected use case is a bracket from one Original Equipment Manufacturer (OEM). The design material for this part is Ti6Al4V, which is also available in the AM sector. The dimensions are approximately $180 \times 110 \times 40 \mathrm{~mm}$. Its modes of failure can be due to overload, a fatigue failure or a creep distortion. The basis of the QP is the standard ASTM 2924-14 "Standard Specification for Additive Manufacturing Titanium-6 Aluminum-4 Vanadium with Powder Bed Fusion" [20].The QP platform has been designed taking into account all previous considerations. In order to meet Study 7 requirements, it is necessary to build the same platform three times and compare their results. 


\begin{tabular}{ll} 
Study type & Description \\
\hline
\end{tabular}

Study 1-Validation of recycled Some powder parameters change if the powpowder der has been recycled, like flow rate, chemical composition, and morphology shape amongst others.

Study 2-Correlation between During the manufacturing process, various powder and bulk material in phenomena, which directly affect the mechanterms of chemical composition ical and chemical properties of the material occur. This study will characterise those dependencies.

Study 3- Bulk material char- The result of this study constitutes the operacterisation into the key factors ating windows in terms of the allowable range limits of each manufacturing variable.

Studies 4- Influence of HIP proThrough this study, the influence of HIP cess in the microstructure and on mechanical and microstructure properties tensile properties have been characterised.

Studies 5- Influence of the Through this study, the influence of HIP and roughness and HIP process in fatigue life surface machining on the fatigue behaviour have been characterised.

Study 6-Demo part validation The aim of this study is to demonstrate that the sample part has similar mechanical and chemical properties as witness specimens.

Study 7-Process reproducibility The aim of this study is to determinate all factors during the QP that can set up reproducibility problems.

Study 8- Material interface The aim of this study is to characterise the analysis quality of the interface between the bulk and added material.

Study 9- Machining the part This study takes into consideration all necand surface preparation essary mechanical and chemical operations to prepare the damaged part for the repair process. 


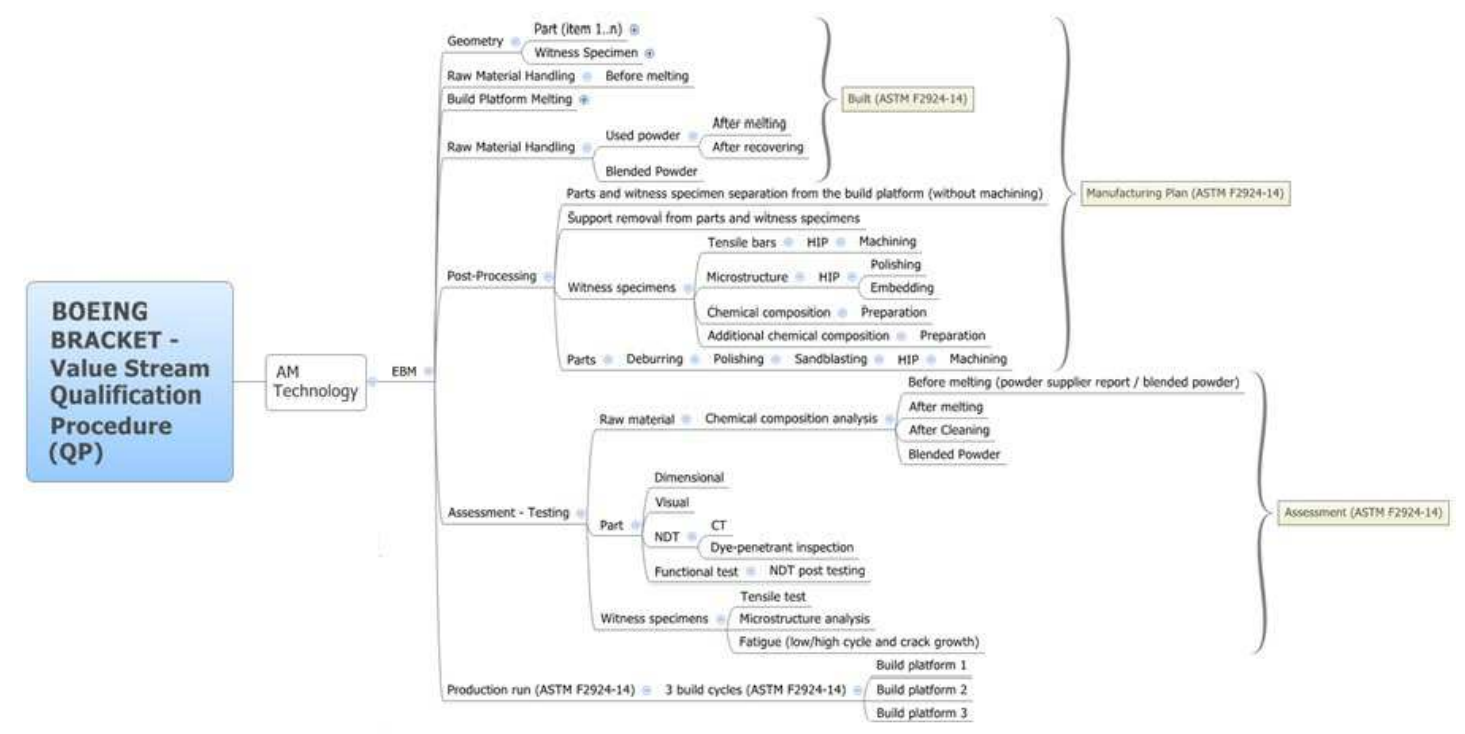

Figure 3: QP aspects to produce the OEM bracket with EBM.

\subsection{Qualification Procedure: building platform}

Components properties depend on its position, in terms of orientation, and its location on the build platform. One of the key aspect during the design of the building platform is the support structure of each part. These do not only hold up the weight of the material during the manufacturing process, but also it works as a heat conductor between the component and the building platform. Residual stresses and deformations after this manufacturing process comes mainly from those thermal gradients and cooling rates in the part [21]. Support structures can be designed in order to minimise the level residual stresses and distortions on the component. The building platform is shown in Figure 4.

Taking into consideration the size of the building platform, it is possible to manufacture two parts at the same time. Only one of them will be HIP processed. This will allow characterising the influence of thermal post-processes on the final part.

In order to identify key building variables and their influence on the final part, the following test samples have been positioned on the building platform (see Table 3). 


\begin{tabular}{|c|c|}
\hline Test sample & Description \\
\hline Chemical composition & $\begin{array}{l}\text { Four different groups of spherical four sam- } \\
\text { ples are located in the first layers (most critical } \\
\text { area) in order to measure the oxygen content } \\
\text { in different locations. Each group has been } \\
\text { built in a different corner of the building plat- } \\
\text { form to evaluate the pick up oxygen-process } \\
\text { along x and y directions. Three spheres with } \\
\text { the same diameter as the ones mentioned be- } \\
\text { fore ( } 5 \mathrm{~mm} \text { ) are linked to the on side of the } \\
\text { part. }\end{array}$ \\
\hline Micro-structure & $\begin{array}{l}\text { Eight test samples have been defined to eval- } \\
\text { uate the final micro-structure in different ori- } \\
\text { entations. The geometry of each witness spec- } \\
\text { imen is a cylinder with a diameter of } 14 \mathrm{~mm} \\
\text { and a length of } 10 \mathrm{~mm} \text {. }\end{array}$ \\
\hline Static mechanical properties & $\begin{array}{l}\text { Following AM machine manufacture guide- } \\
\text { lines, specimens and parts are located at } 15 \\
\text { mm from the building platform. Four tensile } \\
\text { specimens in each orientation are included to } \\
\text { verify that the location in the build platform } \\
\text { is not crucial. }\end{array}$ \\
\hline
\end{tabular}

Some parts shall be HIP treated to improve fatigue behaviour. For this reason witness specimens, except chemical composition samples, shall be HIP treated to achieve the same mechanical properties and microstructure as the final HIP processed part.

\subsection{Qualification Procedure studies}

175 3.2.1. Study 1-Validation of recycled powder

Standard ASTM F2924-14 [20] considers the feedstock as the most important parameter to be controlled during the manufacturing process. Metal powder 


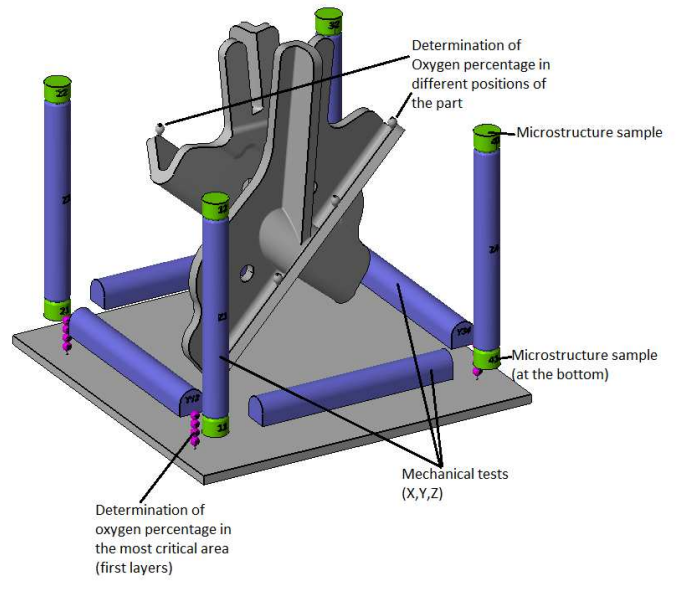

Figure 4: QP building platform

shall contain a maximum amounts of inclusions and impurities. This document establishes an admissible range for each element presented in the alloy. From a chemical composition point of view, mixed powder is allowed as long as its content meets with the cited standard. Other relevant parameters to characterise the powder degradation during the AM build cycles are the flow rate, particle shape, tap density, size distribution, and entrapped porosity. Table 4 correlates this powder characterisation properties with the corresponding standard.

3.2.2. Study 2-Correlation between powder and bulk material in terms of chemical composition

While Study 1 is based on powder characterisation, Study 2 determines the chemical composition of the bulk material. The chemical composition mentioned in the standard ASTM F2924 refers to the processed material.

It is very important to characterise the powder's recyclability. For this purpose, it is important to correlate, in terms of chemical composition, powder and bulk material, both before and after the building process. The chemical tests presented in Table 4 were carried out on the bulk material.

\subsubsection{Study 3-Bulk material characterisation into the key factors}

The aim of this study is to set up the behaviour of AM parts in the limits of the material. In the case, of Ti6 Al4V, the oxygen content is the criterion to 
Table 4: Powder tests based on ASTM Standards [20]

Test Required

Chemical Analysis

Flow Rate

Tap Density

Powder Morphology

Particle Size

\section{Test Standard}

ASTM E2371. Test method for analysis of titanium and titanium alloys by direct current plasma and inductively coupled plasma atomic emission spectrometry.

ASTM E1409. Test method for determination of oxygen and nitrogen in titanium and titanium alloys by inert gas fusion.

ASTM E1447. Test method for determination of hydrogen in titanium and titanium alloys by inert gas fusion thermal conductivity/infrared detection method.

ASTM B213. Test method for flow rate of metal powders using the hall flow-meter funnel.

ASTM B212. Test method for apparent density of free-flowing metal powders using the Hall flow-meter funnel

ASTM E3. Guide for preparation of metallographic specimens.

ASTM E40\%. Practice for micro-etching metals and alloys

ASTM B822. Test method for particle size distribution of metal powders and related compounds by light scattering. 
distinguish between grade 5 for aircraft application and grade 23 for health device application. Therefore, oxygen content defines the allowance bulk-material range.

For the use case, the material has been provided with an oxygen content of $0.14 \%$, which is in accordance with the maximum content proposed by the ASTM F2924 [20]. Table 5 describes all relevant testing for this study.

\subsubsection{Studies 4 and 5-Post processes}

Taking into consideration the high technical specification from the aerospace sector, final components will be subjected to heat treatments, like HIP, to release internal stresses, to improve the mechanical properties and to avoid fatigue issues. The HIP process on AM parts is essential to reduce the porosity as well as to eliminate internal stresses. Good fatigue behaviour is required for aircraft components. The porosity and the roughness typical of AM processes could be a risk for fatigue performance.

The aim of this study is to know the influence of HIP treatment in the microstructure and the tensile stress of Ti6Al4V grade 5 . In addition, the powder bed location and build orientation of the witness specimens have been considered.

\subsubsection{Study 6-Demo part validation}

The aim of this study is to validate a demo part process by AM. To evaluate the conformity of the part, some assessments that have to be considered include:

- Chemical composition

- Dimensional analysis

- Visual inspection

- Non Destructive Testing (NDT)

- Computerised Tomography scan (CTs)

- Dye-penetrant inspection

- Mechanical tests to assess the needed mechanical properties for the Boeing bracket 
Chemical Analysis

Micro-structure

Static Mechanical Properties

Fatigue
ASTM E2371. Test method for analysis of titanium and titanium alloys by direct current plasma and inductively coupled plasma atomic emission spectrometry.

ASTM E1409. Test method for determination of oxygen and nitrogen in titanium and titanium alloys by inert gas fusion. ASTM E144\%. Test method for determination of hydrogen in titanium and titanium alloys by inert gas fusion thermal conductivity/infrared detection method.

ASTM E1941. Test method for determination of carbon in refractory and reactive metals and their alloys by combustion analysis.

EN 3976. Chemical analysis for the determination of hydrogen content.

ASTM E3. Guide for preparation of metallographic specimens. ASTM E40\%. Practice for micro-etching metals and alloys. ASTM E112. Test methods for determining grain size.

EN 2003-4. Determination of surface contamination (Part:9). ASTM E8M. Test methods for tension testing of metallic materials.

ISO 6892. Tensile testing - Part 1: Method of test at room temperature.

$A S T M E 466$. Standard practice for conducting force controlled constant amplitude axial fatigue tests of metallic materials (high-cycle fatigue).

ASTM E606. Practice for strain-controlled fatigue testing (low-cycle fatigue).

ASTM E64\%. Test method for measurement of fatigue crack growth rates (fatigue crack growth). 


\subsubsection{Study 7-Process reproducibility}

The aim of this study is to demonstrate the reproducibility of the manufacturing and repair processes. Or in other words: that the characteristic parameters of all the parts produced in any given batch will be within tolerance if the same raw material is used, the same steps are followed, and the machines use the same settings.

This is a four-part problem in which the first step is to determine the probability distributions of the characteristics parameters of the part (e.g.: dimensions, yield and tensile strength) assuming the process is followed correctly. These deviations are caused by factors that cannot be fully controlled and that affect the final product (e.g.: temperature fluctuations of the melting pool, oscillations in the chamber pressure and temperature).

The second step is focused on establishing the correlation between the properties of the final part and those parameters that can be controlled and/or monitored during the process (e.g.: chamber temperature, beam velocity). This information will be used to determine which process data have to be captured and analysed to ensure parts comply with their requirements. The reason these correlations must be understood is that some properties cannot be tested without damaging the part and rendering it unusable (e.g.: tensile strength, corrosion rate). This can be achieved by performing sensitivity analyses by using models and simulations, producing multiple samples and testing them, or by a combination of both techniques.

The third step is to determine the number of samples that will have to be inspected and tested from each batch in order to guarantee with a certain level of confidence that all parts meet the requirements. Manufacturing in the aerospace industry is held to particularly high standards and it is not uncommon to inspect all part from each batch. For parts being repaired the variability of the characteristics of repair mean that every part has to be inspected.

The fourth element of process reproducibility focuses on the traceability of parts and the storage and sharing of the data used and produced throughout the manufacturing or repair process. This demands for a repository that stores all the information about the AM technology, material, geometry (STL and sliced files), build samples, post-processing, and the build platform. Figure 5 shows 


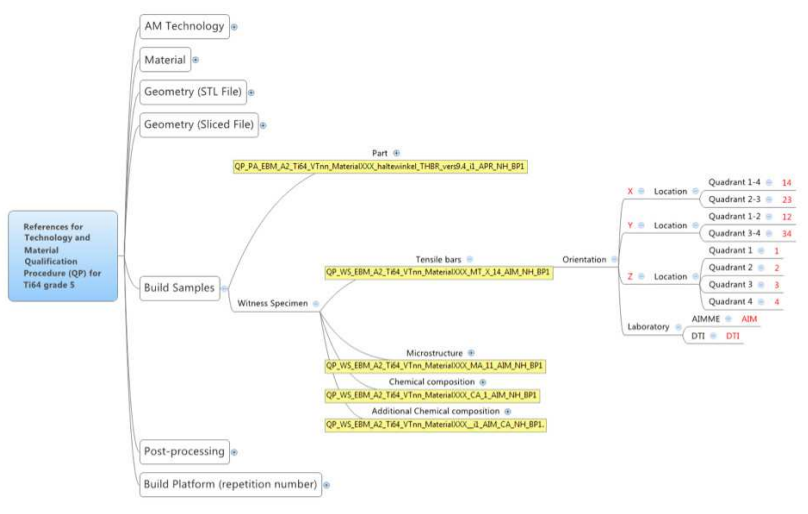

Figure 5: References for "build samples".

how this strategy was implemented as part of the QP for parts produced with Ti6Al4V. original part.

After having reviewed all AM standards and due to the lack of specific procedures for these technologies, it has been concluded that the best way to evaluate the level of interface imperfections by applying welding standards (see Table 6).

The aim of this study is the assessment of AM material which better fits with a specific base material, and to obtain optimal AM process parameters to achieve the best joining possible.

\subsubsection{Study 9-Machining the part and surface preparation}

For AM repair it is necessary to control not only the position of the failure part in the platform but also the cleanliness of the surface.

All particularities of the machining of the part and some experiments of different surface preparation processes must be developed to obtain a general 


\begin{tabular}{|c|c|}
\hline Test required & Test Standard \\
\hline Static mechanical properties & $\begin{array}{l}\text { ISO 9015-1. Destructive tests on welds in } \\
\text { metallic materials - Hardness testing - Part } \\
\text { 1: Hardness test on arc welded joints. }\end{array}$ \\
\hline Impurities and defects & $\begin{array}{l}\text { ISO 581\%. Fusion-welded joints in steel, } \\
\text { nickel, titanium and their alloys (beam weld- } \\
\text { ing excluded) - Quality levels for imperfections }\end{array}$ \\
\hline
\end{tabular}

procedure to guarantee a successful joining of two materials of different natures.

\section{Results}

This section presents and analyses the obtained results of the proposed studies during the designed QP for the use case. Figure 6 shows the witness specimens and parts manufactured following the designed QP process.
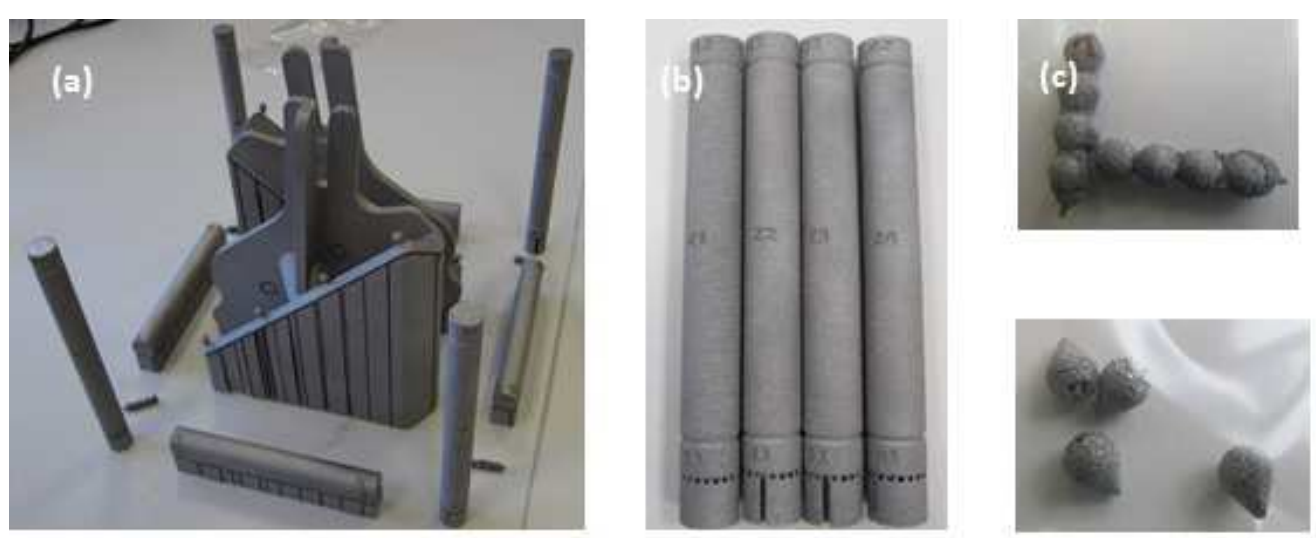

Figure 6: (a) A build platform. (b) Tensile bars with the microstructure and porosity coupons linked. (c) Chemical tests samples.

For Ti6Al4V grade 5, HIP process reduces almost completely the internal porosity (see Figure 7), which improves the fatigue behaviour of the part. Furthermore, HIP process increases the columnar grain size in both, width and length; and also it increases the thickness of the $\alpha$ phase along the build direc- 
tion (see Figure 11 (a) and (b)). In general, the size of $\alpha$ phase colony is very small and it the majority of cases they are presented following a Widmanstätten structure (see Figure 11 (c) and (d)). Not only $\alpha$ phase concentration has changed after HIP, but also dislocations density in the acicular $\alpha$ phase grains has been reduced [22]. This improves the ductility of the material (see Figure 8 (b)). The level of impurities is below the maximum specified in the technical requirements of the part.

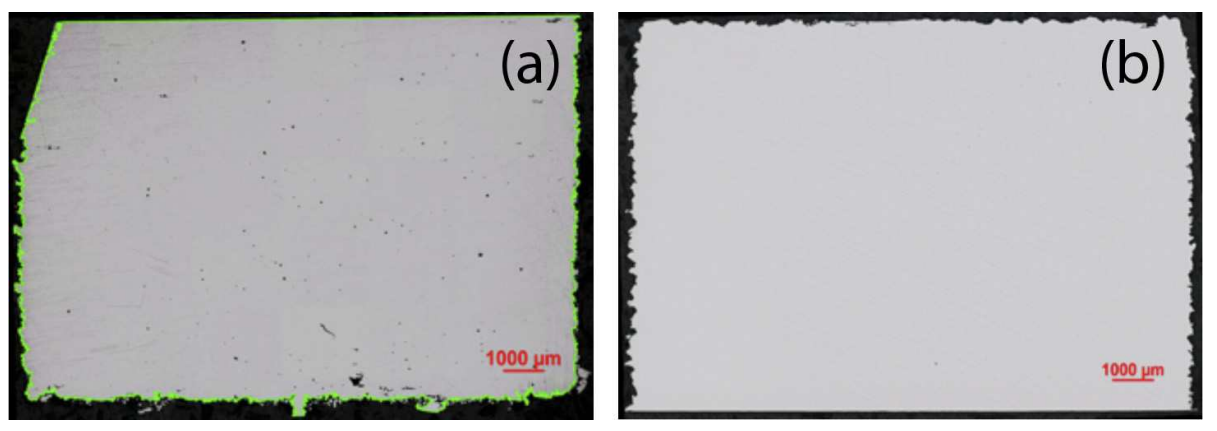

Figure 7: Porosity results. (a) No HIP; (b) HIP.
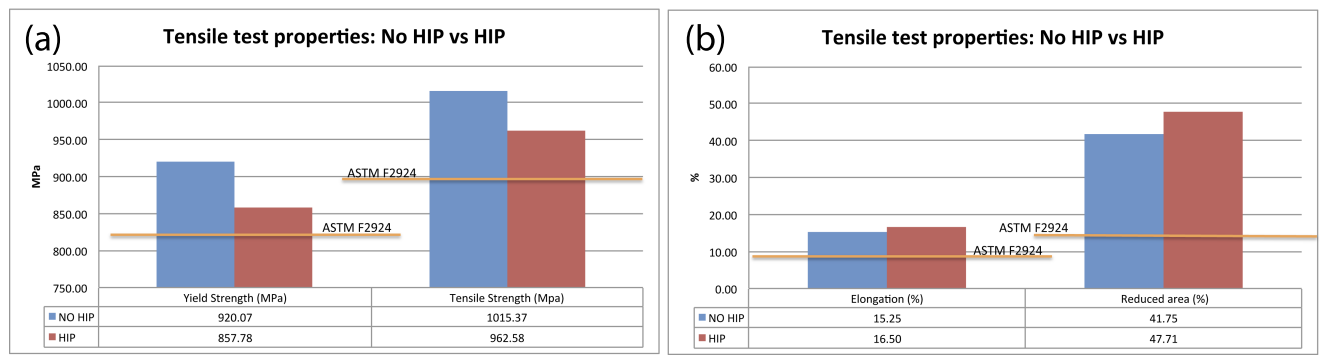

Figure 8: Static mechanical properties with and without HIP treatment.

Figure 10 shows there are small changes on the mechanical properties depending on the manufacturing direction. However, all of them are over the minimum established by the OEM. This feature resulting from the manufacturing process, must be taken into consideration during the design of the part to optimise its mechanical properties.

As a conclusion, HIP treatment modifies the micro-structure and reduces slightly the static mechanical properties of the part (see Figure 10). It improves the porosity level, and thus the fatigue behaviour of the part. The level of im- 


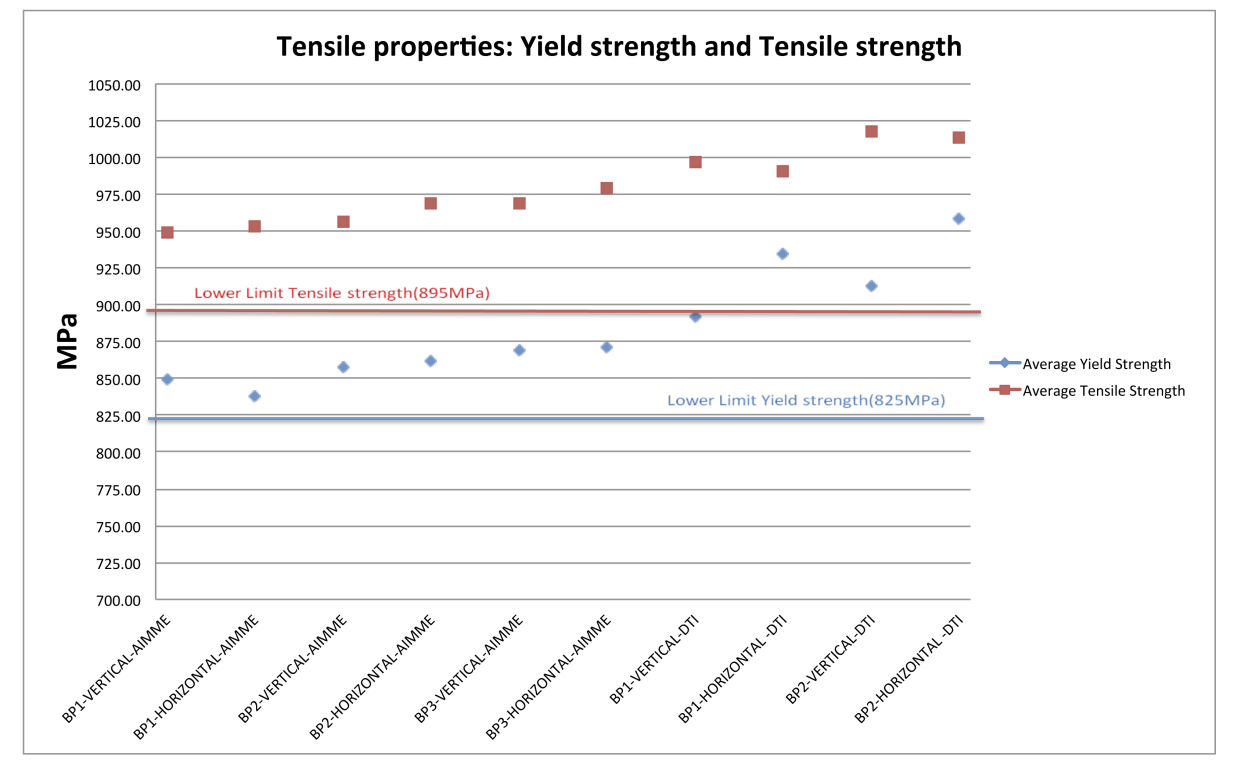

Figure 9: Static mechanical properties with HIP for different specimens.
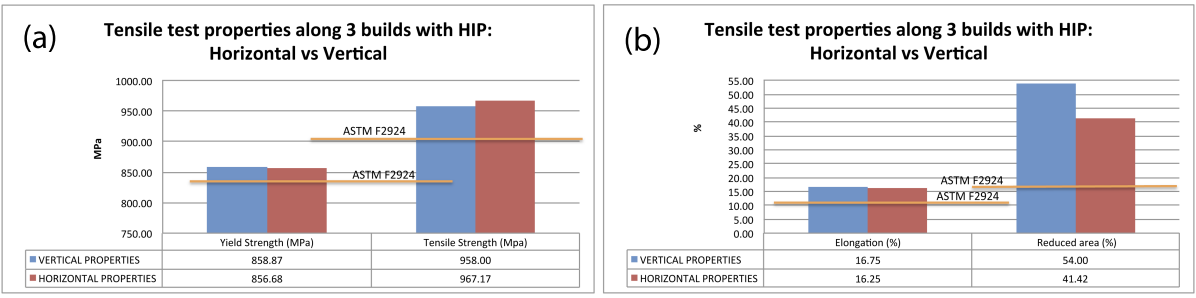

Figure 10: Horizontal/Vertical static mechanical properties with HIP.

purities has not been affected by the this process. All obtained values complain with OEM specifications (see Figure 9). 
(a)

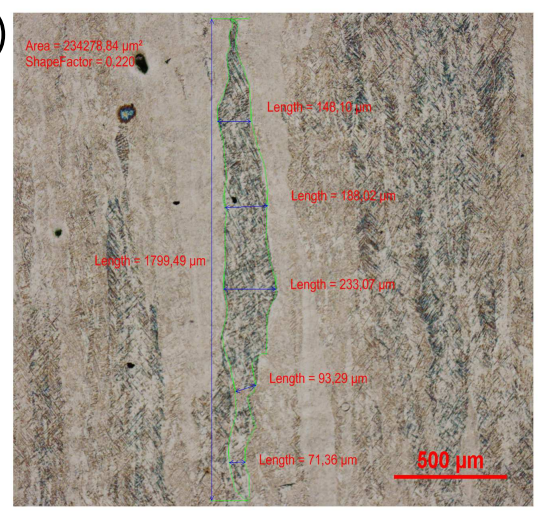

(c)

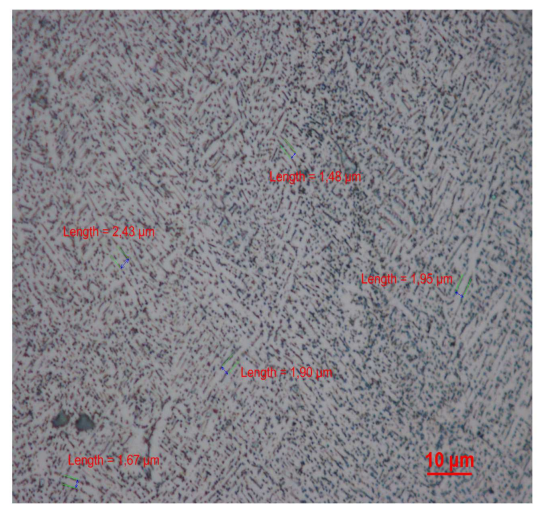

(b)

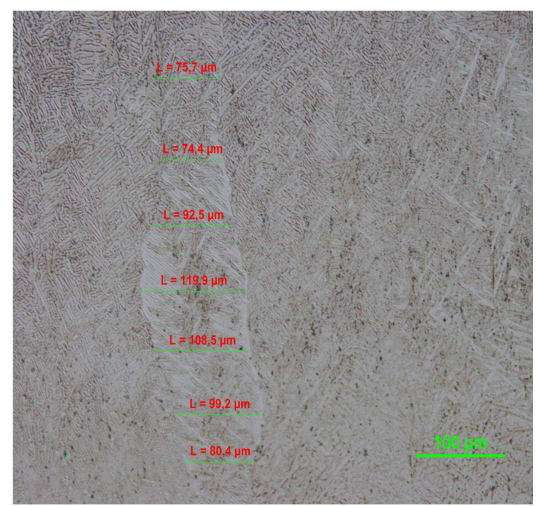

(d)

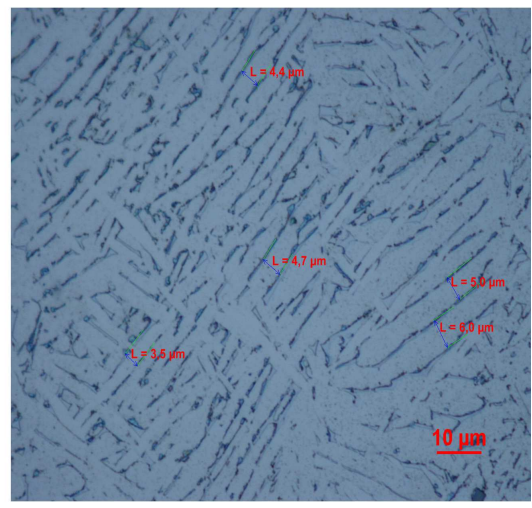

Figure 11: Vertical section view for an EBM microstructure sample. Individual columnar grains: (a) No HIP; (b) HIP. Thickness of -plates: (c) No HIP; (d) HIP.

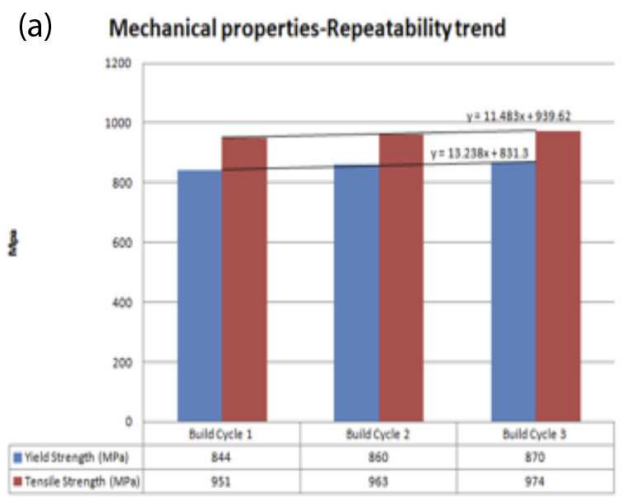

(b)

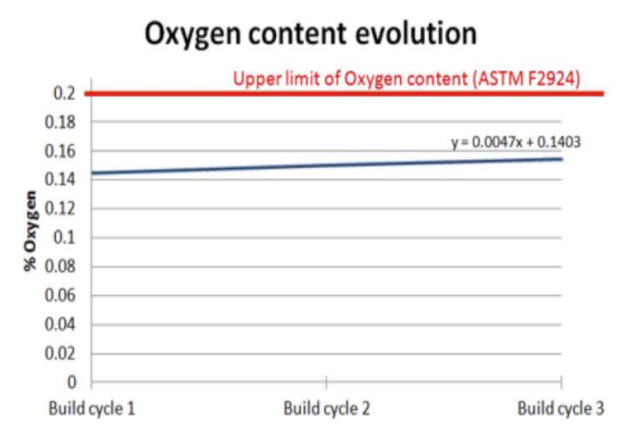

Figure 12: (a) Repeatability of the mechanical properties with HIP. (b) \% Oxygen pick up in bulk material. 
It is important to highlight the repeatability of the mechanical properties along the difference building cycles achieved by the procedure (see Figure 12 (a)). After analysing the oxygen pickup at the tests specimens, it has been conclude that all of them are below the upper limit specified by ASTM F292414 (see Figure $12(\mathrm{~b})$ ).

\section{Conclusions}

EBM and some other AM technologies (e.g.: Laser Cladding and WAAM) are currently used as a manufacturing process for metal parts in various industries. To implement them in the aerospace industry, it is necessary not only to demonstrate their manufacturing capabilities (the AM community is dedicating significatn resources to improving their technology maturity) but also to comply with all aerospace technical and management requirements.

Incorporating AM into aerospace manufacturing or repair processes entails many issues related to "quality" that must be developed and established. Prior to developing $\mathrm{QA} / \mathrm{QM}$ procedures, which include all the particularities related to the nature and characteristics of the technology, the following aspects must be achieved:

- Key factors and variables of the technology

- Correlation between product and process specification

- Ensuring the reproducibility of the manufacturing process

To fulfil these criteria, a new QP has been developed taking into account the particularities of EBM. It t has then been applied to a real use case, the Boeing "bracket". All the achieved results are in accordance with the standards and the technical requirements of the part. Following this procedure, the correspondent key variables for reproducing this part have been identified and defined.

Once this QP has been designed and put into practice, General Procedures, Operational Instructions, and Control Procedures related to QA/QM procedures need to be developed for these AM processes.

This paper represents the first steps towards a consistent set of QA/QM procedures that comply with all management, control and assurance requirements 
in the aerospace industry. However, there are quality issues that need to be resolved before implementing AM as a manufacturing or repair technology.

- Standardization is not well established. As has been mentioned, there are many committees working to overcome this challenge. The ASTM Committee is probably the most advanced in this respect

- New advanced NDT techniques capable of detecting critical defects with a high degree of certainty

- To process more complex parts new materials, like Rene 95 or N500, need to be processed with this technology. Proper operating windows for each machine and new materials must be established

- Final accuracy and surface finish must be improved in order to avoid additional post-processes. These affect the economic advantages of these technologies

- New on-process quality systems need to be implemented in order to verify in each layer some particular quality aspects, including porosity, lack of fusion and accuracy amongst others

A roadmap for Qualifying AM technologies has been described based on the knowledge of the variables which rule the process, not only the AM itself if not its relationship with after melting processes such as surface and heat treatment; on the process specification; and on the data generated according to the process specified.

A guide for AM QP of Ti6Al4V using full-melt powder bed fusion has been specified, including procedures for the assessment of the variables among the manufacturing or repairing process and the corresponding results. This guide is based on novel AM standards such as ASTM F2924-14.

This procedure has been applied to a use case provided by an OEM as demo part. The component requirements and the corresponding manufacturing plan for qualification has been specified. The assessment of the feedstock, bulk material and component properties are conducted along three build cycles. Finally, the results of the tests has been exposed. 
This guide could be considered as reference for other metal alloys using full melt powder bed fusion such as Selective Laser Melting (SLM).

\section{Acknowledgements}

The work presented in this paper has received funding from the European Union's Seventh Framework Programme (FP7/2007-2013) under grant agreement number 605779 . This research was also supported in part by the IVHM Centre at Cranfield University and AIMME-Instituto Tecnológico Metalmecánico.

\section{References}

[1] Lyons B. Additive manufacturing in aerospace; examples and research outlook. The Bridge 2012;42.

[2] Wissenbach K. Flexible and near-net-shape generative manufacturing chains and repair techniques for complex shaped aero engines parts. Tech. Rep. 13361; European Commission; 2007.

[3] Bourell D L, Beaman J B, Leu M C, Rosen D W. A brief history of additive manufacturing and the 2009 roadmap for additive manufacturing: Looking back and looking ahead. In: RapidTech: US-Turkey Workshop on Rapid Technologies. Instabul Technical University; Tennesse Technological University; 2011,.

[4] Gasser A, Backes G, Kelbassa I, Weisheit A, Wissenbach K. Laser additive manufacturing. laser metal deposition (lmd) and selective laser melting (slm) in turbo-engine applications. Laser Technik Journal 2010;7:58-63.

[5] Khajavi S H, Partanen J, Holmstrm J. Additive manufacturing in the spare parts supply chain. Computers in Industry 2014;65:50-63.

[6] Kelbassa I, Albus P, Dietrich J, Wilkens J. Manufacture and repair of aero engine components using laser technology. In: Proceedings of the 3rd Pacific International Conference on Application of Lasers and Optics 2008. PICALO; 2008, p. 208. 
[7] Mellor S, Hao L, Zhang D. Additive manufacturing: A framework for implementation. International Journal of Production Economics 2014;149:194201.

395 [8] Arcella F, Froes F H. Producing titanium aerospace components from powder using laser forming. JOM 2000;52:28-30. J2: JOM.

[9] Deppe G, Koch R. Exploring the influence on an additive manufacturing integration on future mro processes in aeronautics. In: RapidTech. Universitt Paderborn; 2014,.

400 [10] Groneck D, Harmon D. Design development of unitized titanium structure. Journal of Engineering for Gas Turbines and Power 2003;125:252-256.

[11] EASA. Certification specifications and acceptable means of compliance for large aeroplanes cs-25. Amendment 15, July.

[12] Chan K S, Koike M, Okabe T, Mason R L. Fatigue life of titanium alloys fabricated by additive layer manufacturing techniques for dental implants. Metallurgical and Materials Transactions A: Physical Metallurgy and Materials Science 2013;44:1010-1022.

[13] Koike M, Martinez K, Guo L, Chahine G, Kovacevic R, Okabe T. Evaluation of titanium alloy fabricated using electron beam melting system for dental applications. Journal of Materials Processing Technology 2011;211:1400-1408.

[14] Gibson I, Rosen D W, Brent S. Additive Manufacturing Technologies : Rapid Prototyping to Direct Digital Manufacturing. New York: Springer; 2010.

[15] Shiomi M, Osakada K, Nakamura K, Yamashita T, Abe F. Residual stress within metallic model made by selective laser melting process. CIRP Annals - Manufacturing Technology 2004;53:195-198.

[16] Vrancken B, Thijs L, Kruth J P, Humbeeck J V. Microstructure and mechanical properties of a novel titanium metallic composite by selective laser melting. Acta Materialia 2014;68:150-158. 
[17] Juechter V, Scharowsky T, Singer R F, Krner C. Processing window and evaporation phenomena for ti6al4v produced by selective electron beam melting. Acta Materialia 2014;76:252-258.

[18] Thijs L, Sistiaga M L M, Wauthle R, Xie Q, Kruth J-P, Humbeeck J V. Strong morphological and crystallographic texture and resulting yield strength anisotropy in selective laser melted tantalum. Acta Materialia 2013;61:4657-4668.

[19] Gong X, Anderson T, Chou K. Review on powder-based electron beam additive manufacturing technology. EDP Sciences 2014;.

[20] F42 A C. F2924-14: Standard specification for additive manufacturing titanium-6 aluminium-4 vanadium with powder bed fusion. 2014 .

[21] Jamshidinia M, Kong F, Kovacevic R. The coupled cfd-fem model of electron beam melting. ASME Distric F-Early Career Technical Confeence 2013:12:163-171.

${ }_{435}$ [22] Murr L E, Gaytan S M, Ramirez D A, Martinez E, Hernandez J, Amato $\mathrm{K} \mathrm{N}$, et al. Metal fabrication by additive manufacturing using laser and electron beam melting technologies. Journal of Materials Science \& Technology 2012;28:1-14. 
(a)

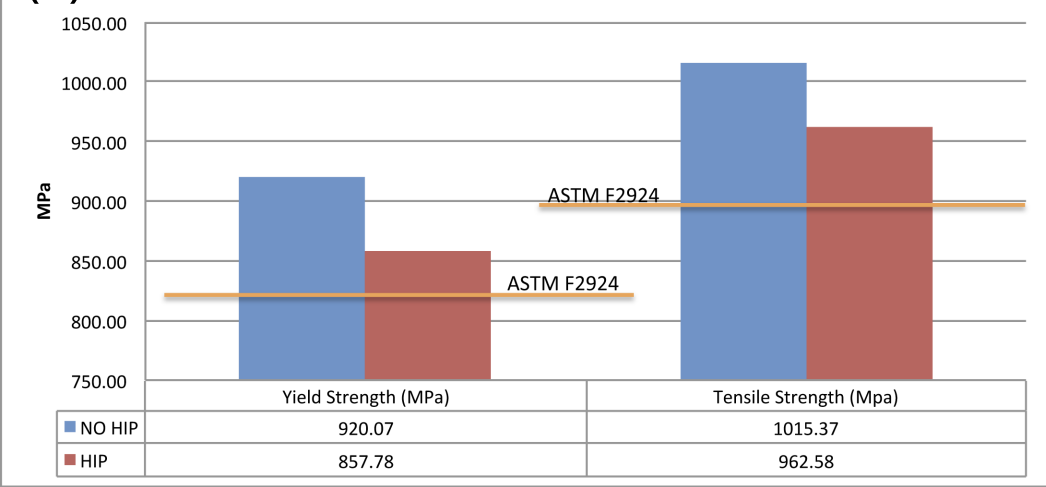

(b)

Tensile test properties: No HIP vs HIP

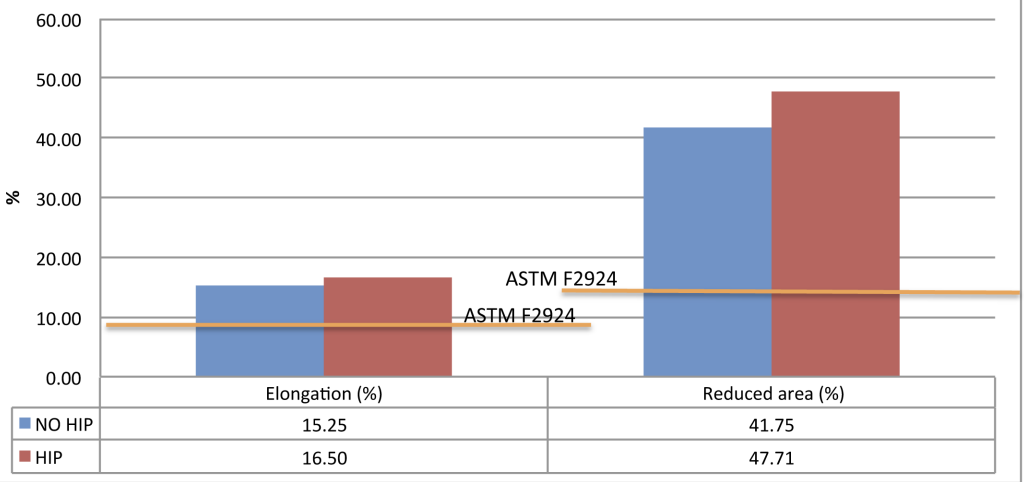


Tensile properties: Yield strength and Tensile strength

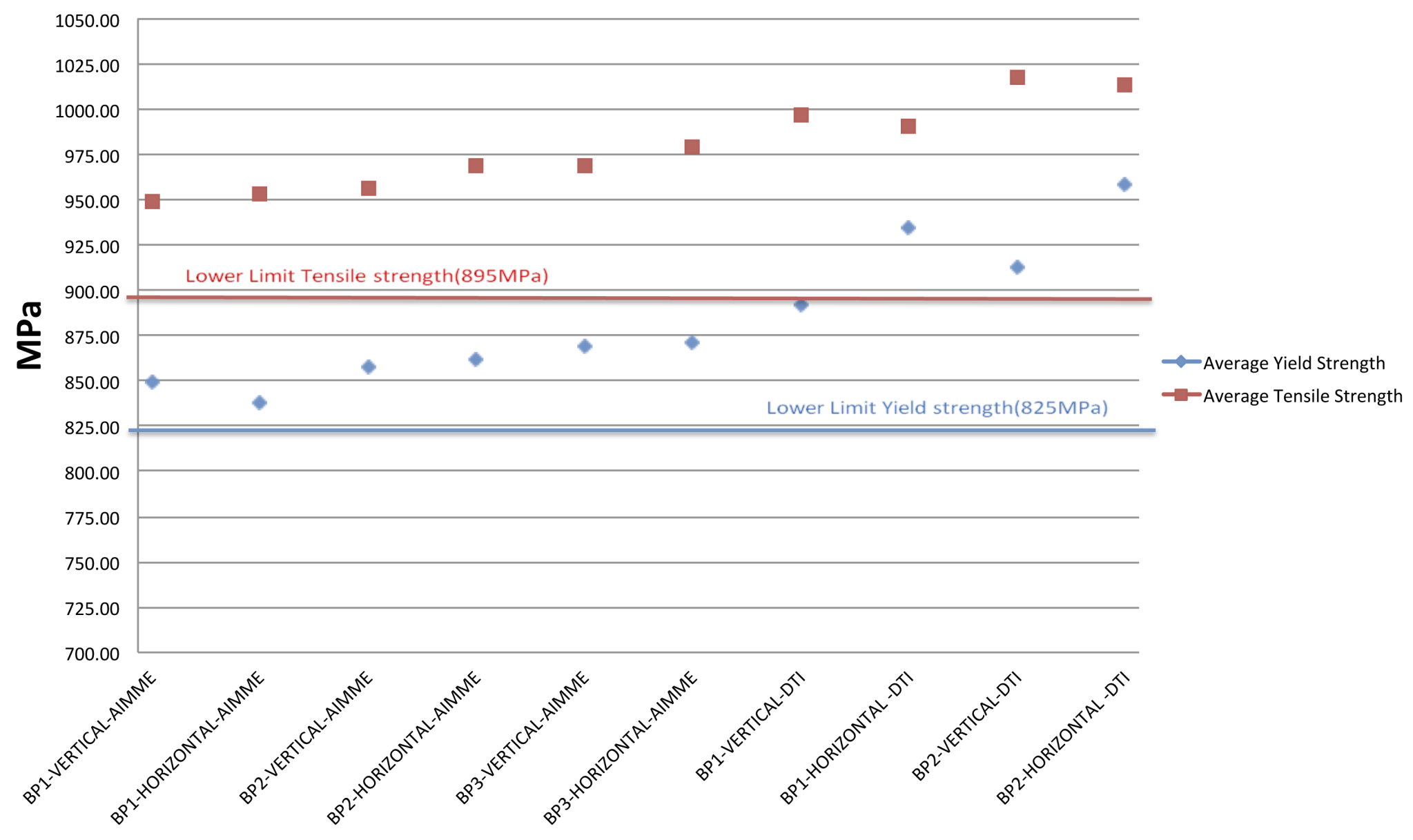



(a) Tensile test properties along 3 builds with HIP:
Horizontal vs Vertical

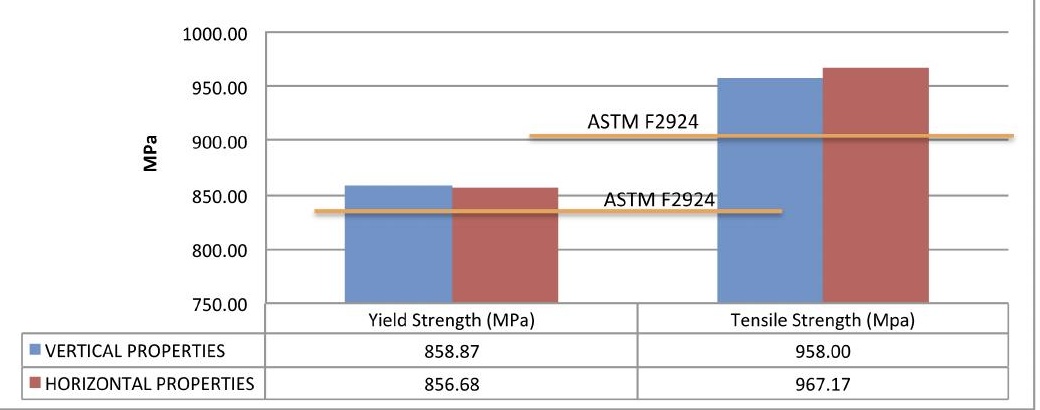

(b) Tensile test properties along 3 builds with HIP:

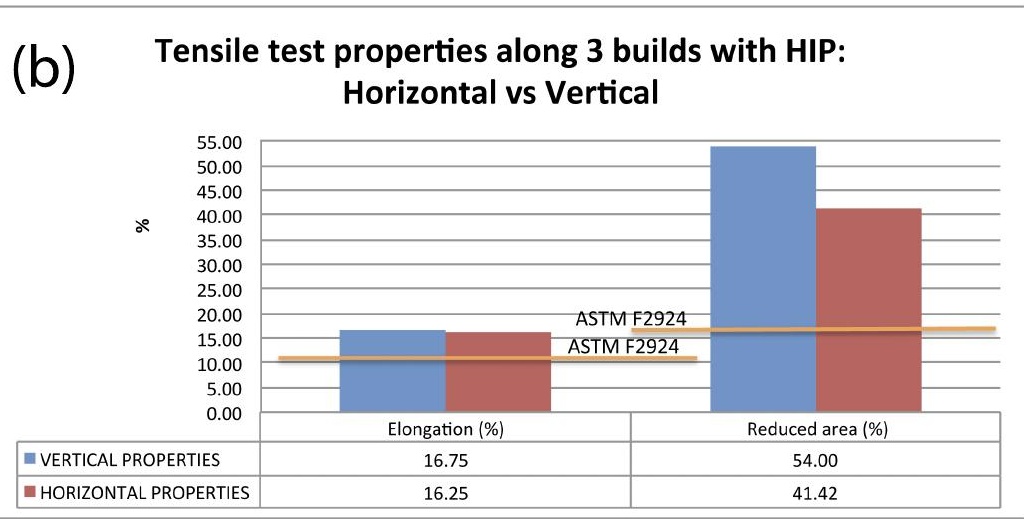


(a)

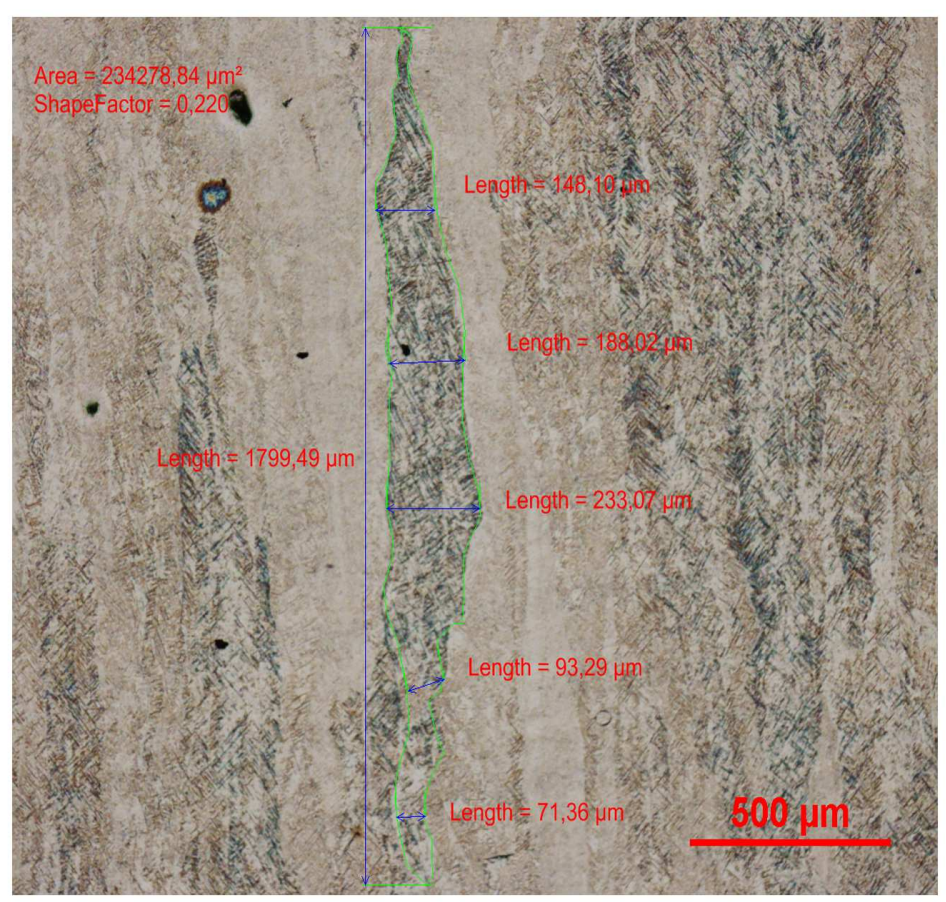

(c)

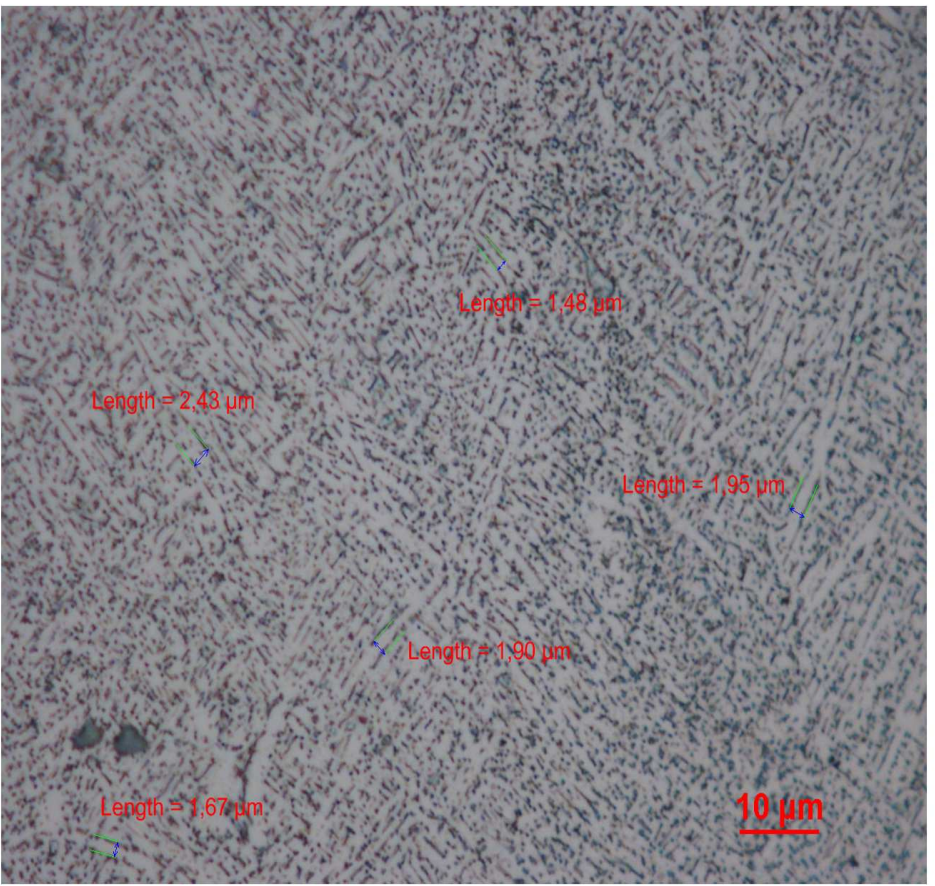

(b)

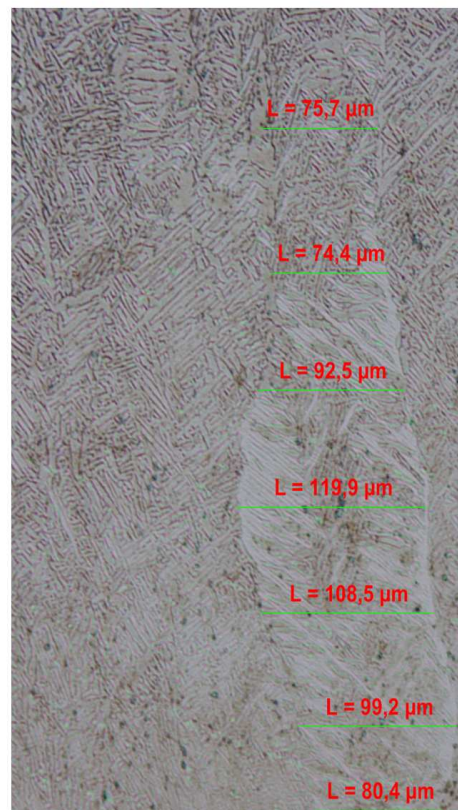

(d)

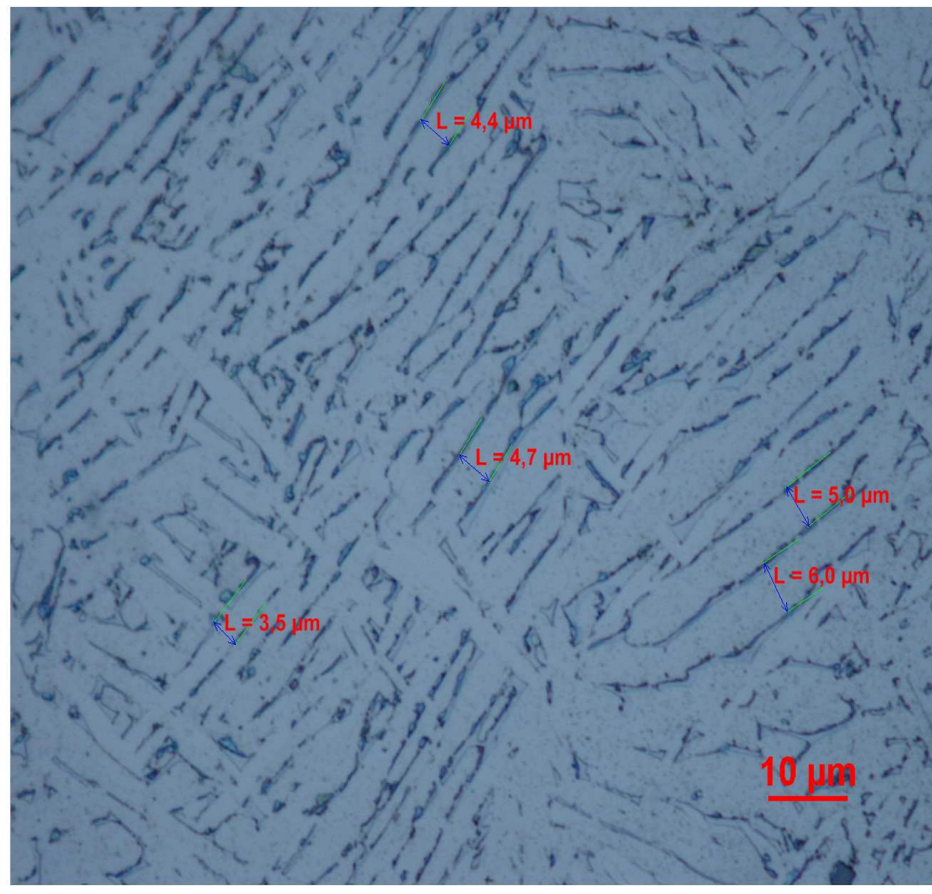


Click here to download high resolution image

\begin{tabular}{c} 
PROCESSQUALIFICATION: \\
$\begin{array}{c}\text { To identify the key factors for insuring the } \\
\text { technical requirements and the } \\
\text { reproducibility }\end{array}$ \\
\hline
\end{tabular}

\section{PRODUCTION:}

To verify if the process is under control for insuring the technical requirements, the reproducibility and traceability.

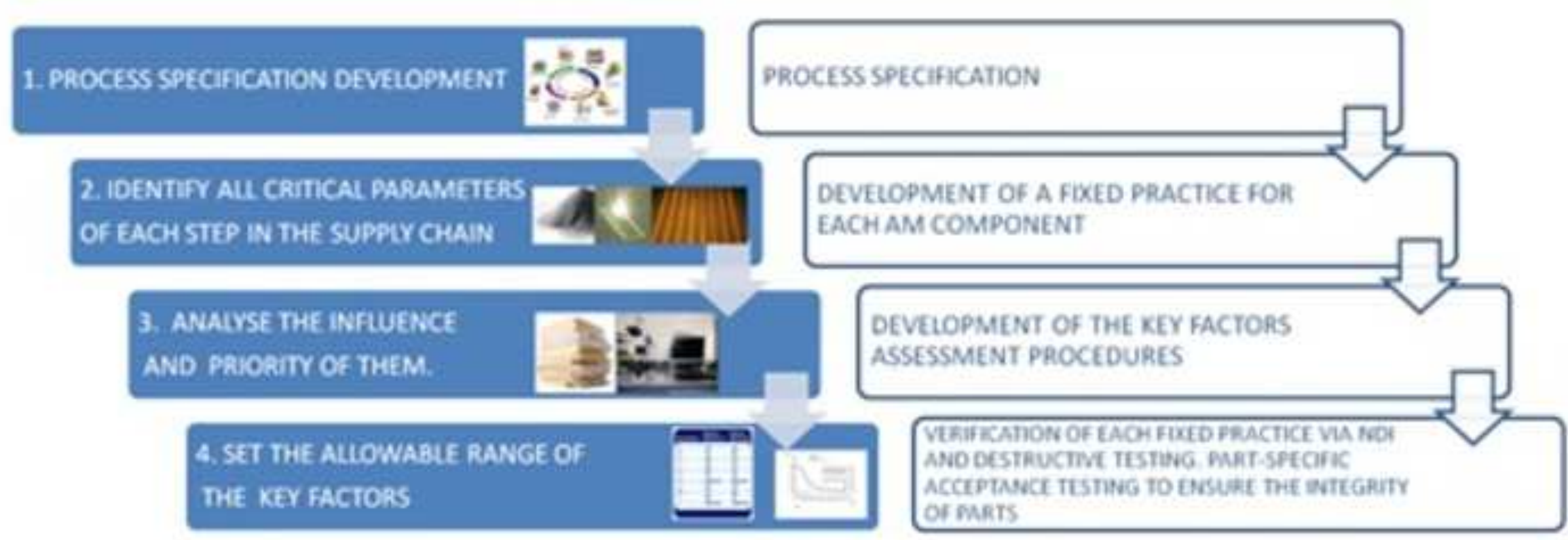

reproducibility 
Click here to download high resolution image

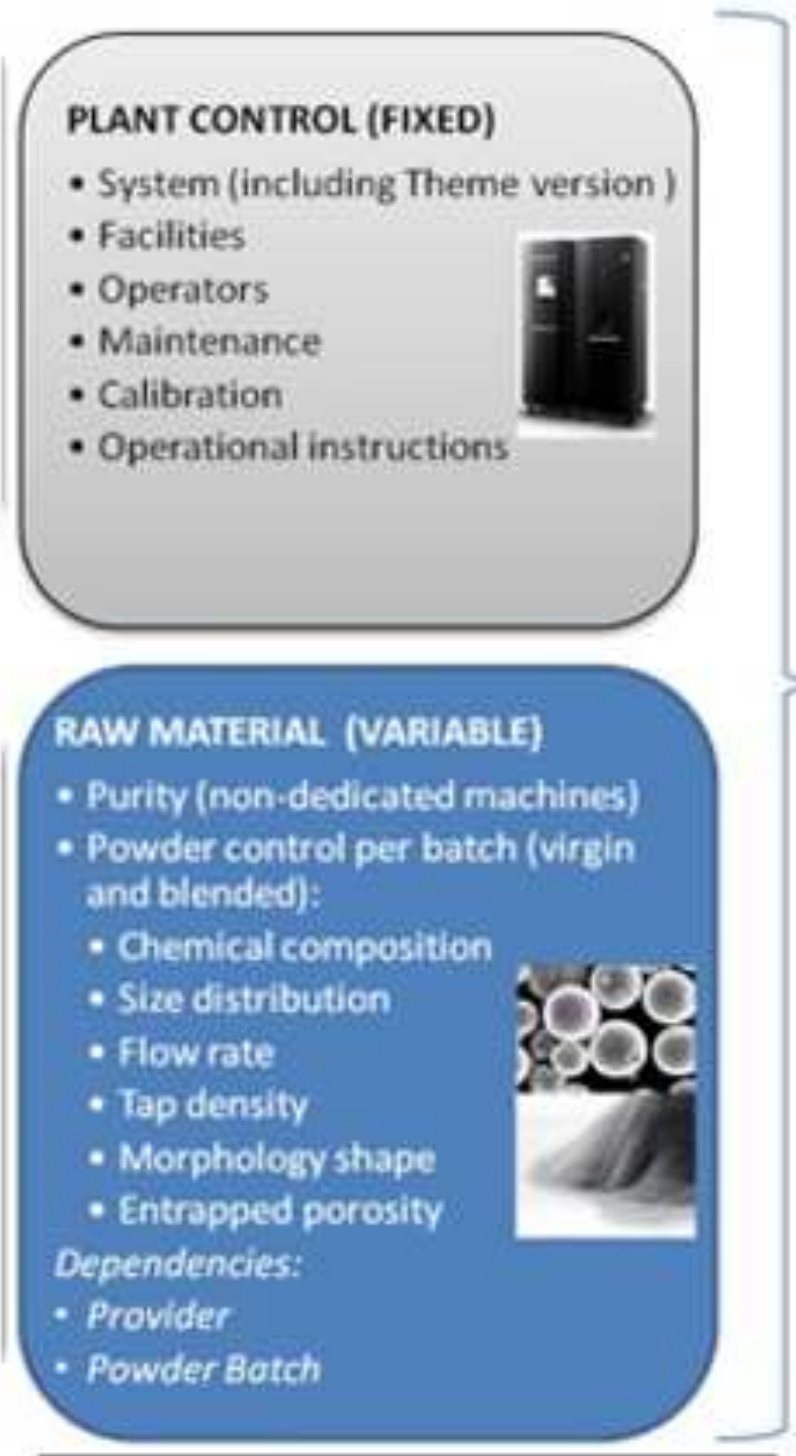

STUDY 1. VAUDATION OF RECYCLED POWDER
STUDY 2. CORAELATION

BETWEEN POWDER AND BULK

MATERIAL IN TEROAS ON

CHEMICAL COMPOSITION.

STUDY 3. BULK MATERIAL

CHARACTERISATION INTO THE

KEY FACTORS LIMITS.

STUDV8. MATESaL

INTERARCEANALYSIS

BULK MATERIAL

(witness specimens)

- Chemical composition

- Microstructure

- Tensile testing

- Fatigue testing

- Dimensions

Dependencies:

- Bed locotion (along X-Y axis and $Z$ axis)

- Build direction (X, Y and Z axis)

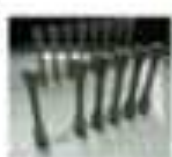$$
\text { axis) }
$$

STUDY 4. INFIUENCE OF

THE HIP PROCESS IN THE

MICROSSTRUCTURE AND

TENSILE PROPLRTIES.

STUDY 5. INFLUENCE OF

THE ROUGHNESS AND MIP

PROCESS IN FATIGUE TEST.

\section{POST PROCESSES}

(witness specimens)

- Roughness:

- As AM

- Machined

- Heat treatments:

- Stress Relief

- hip

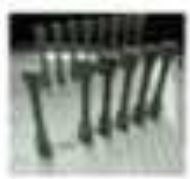

STUDY 6. DEMO PART

VAUDATION.

STUDY9. MACHINING THE

PART WOSUAFACE

PREPARATION

\section{PART}

- Chemical composition

- Dimensions

- Visual inspection

- NDT:

- Computerised Tomography Scan (CT)

- Dye-penetrant inspection

- Qualification tests per demostrator part

- Visual inspection post testing

- NDT post testing

STUDY 7. PROCESS REPRODUCIBIUTY.

- Traceability: geometry, powder, part, post-processes.

- Test results: powder, bulk material (witness specimens) and parts.

- Plant control and procedures.

- Key factors to be monitored

- QM/QC development 


\section{Figur}

Click here to download high resolution image

BOEING
BRACKET -
Value Stream
Qualification
Procedure
(QP)

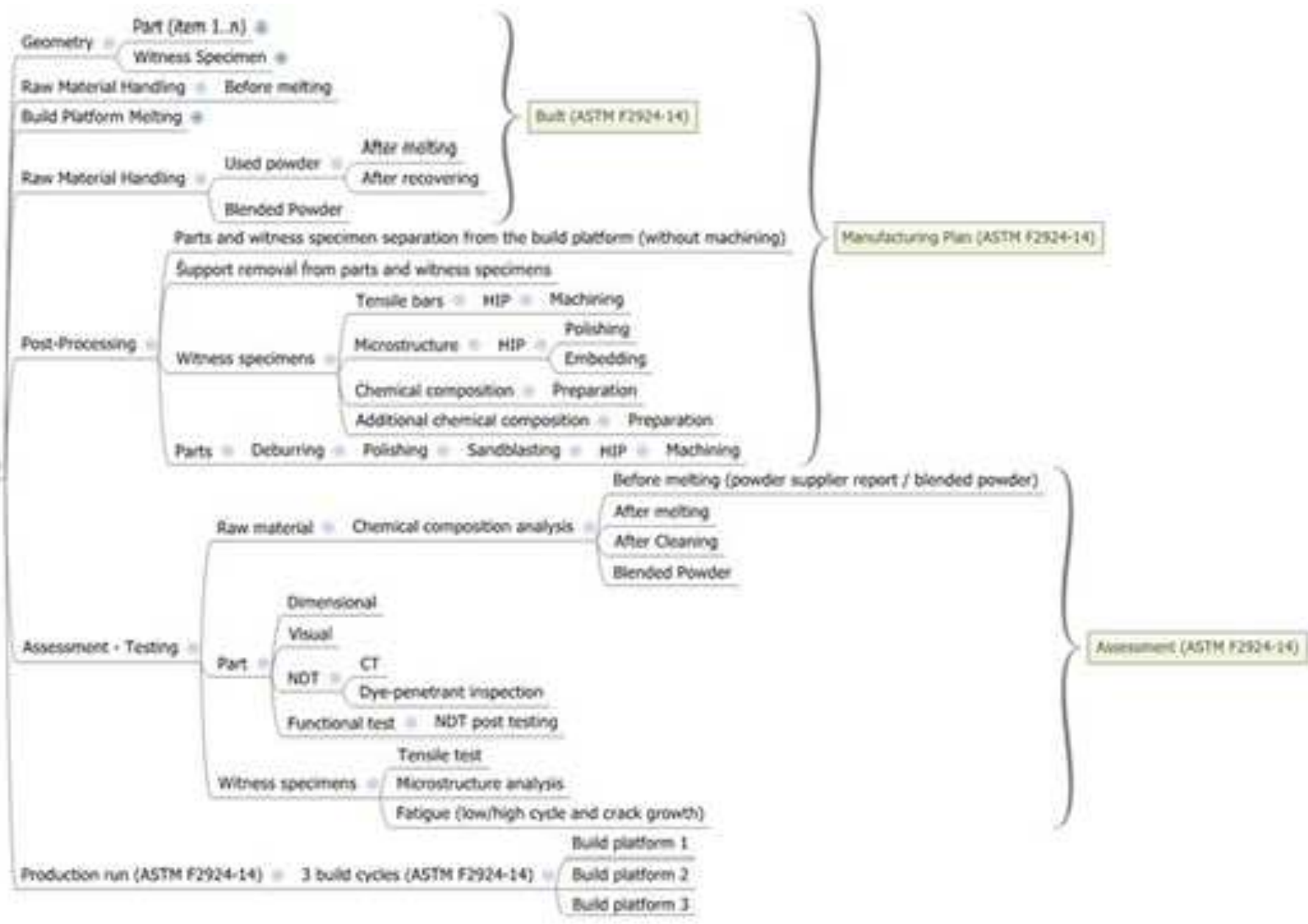




\section{Figure}

Click here to download high resolution image

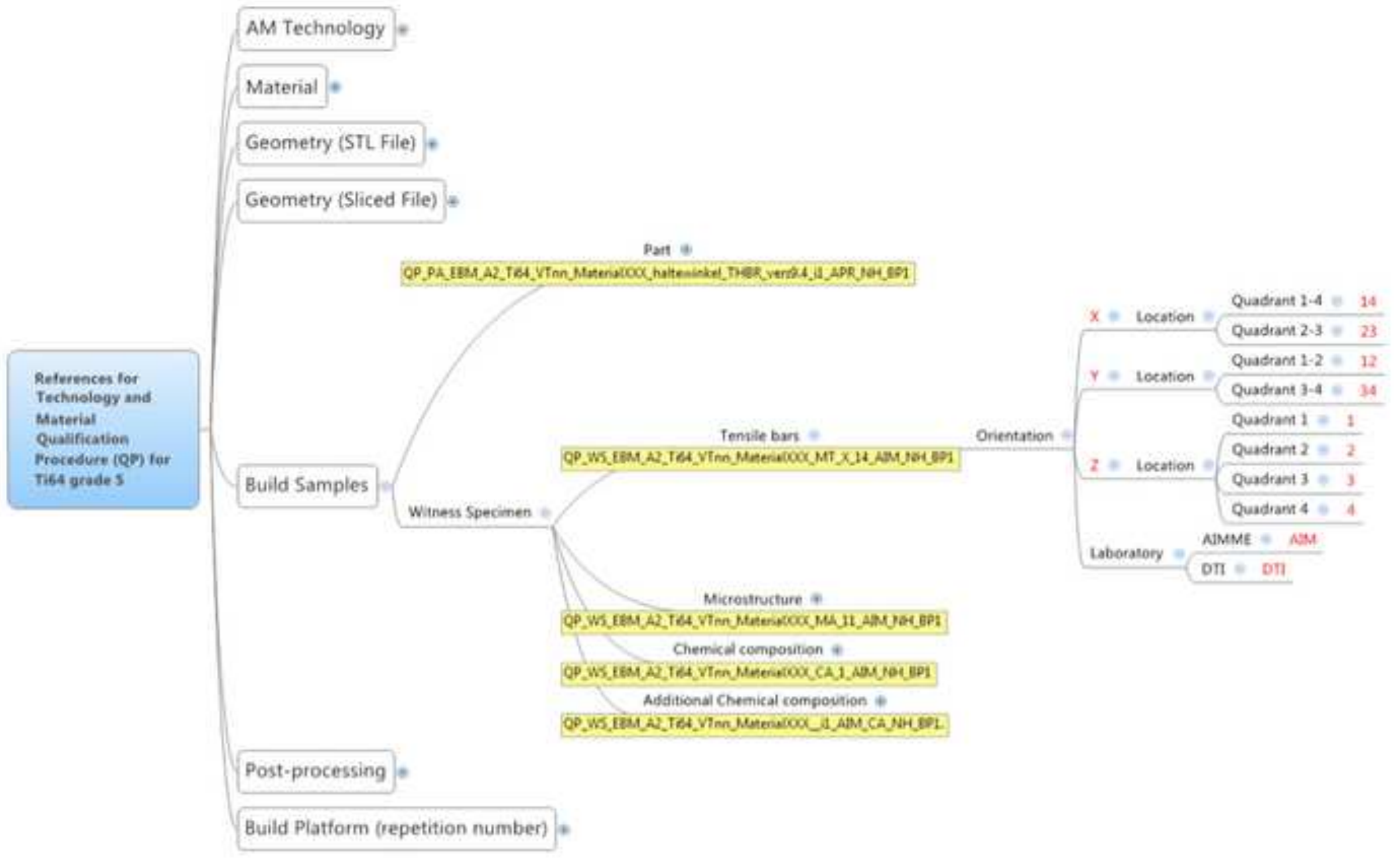



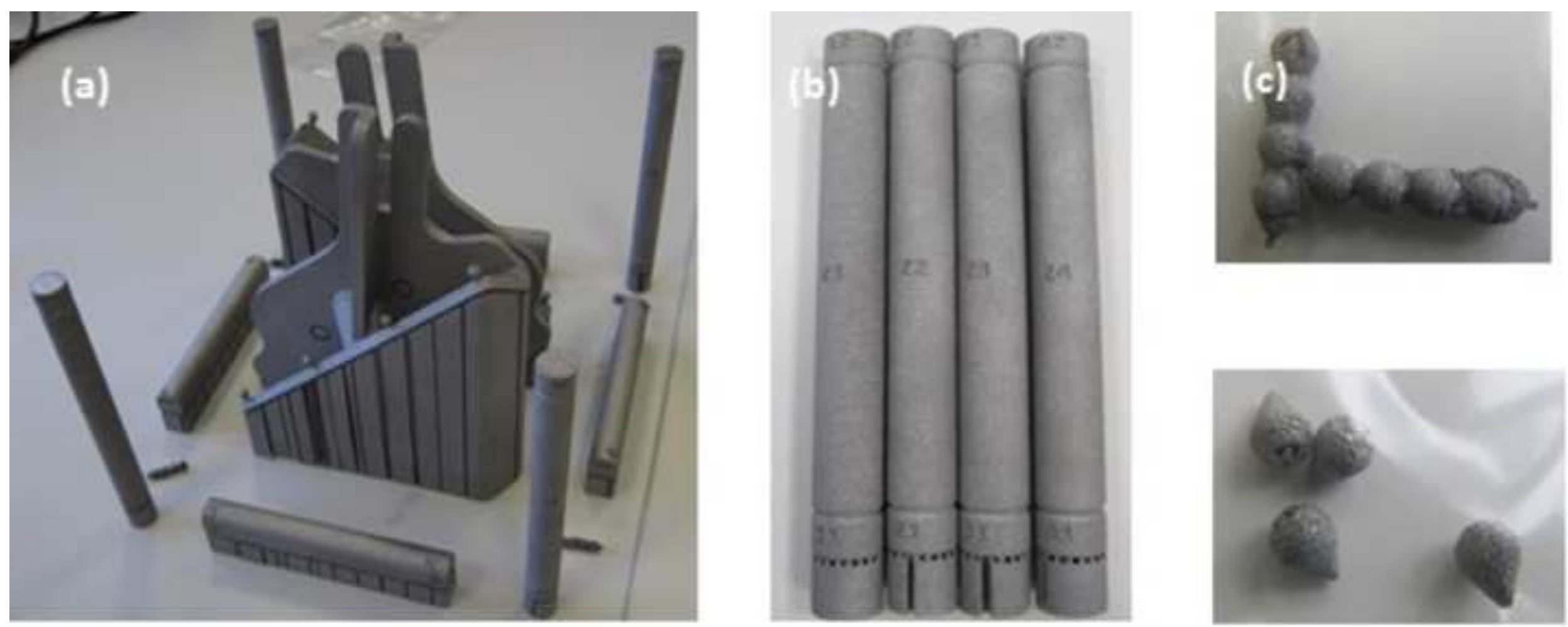
Figure
Click here to download high resolution image
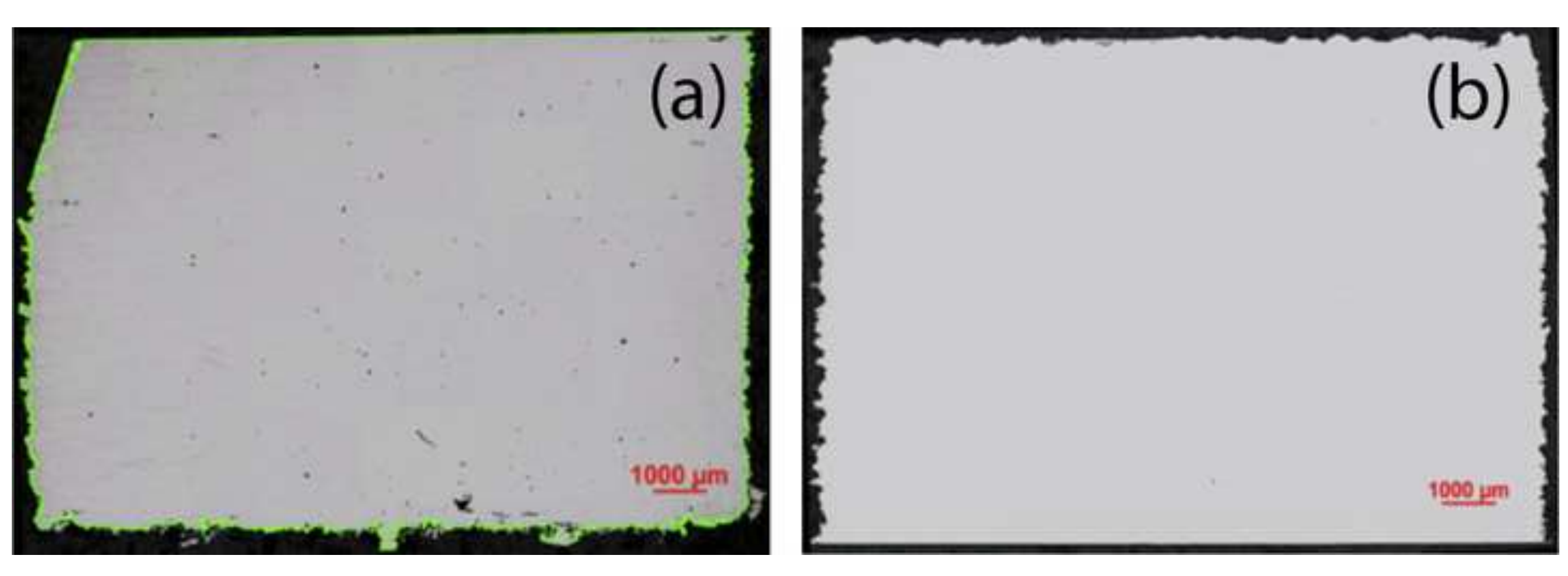

1000 بm 


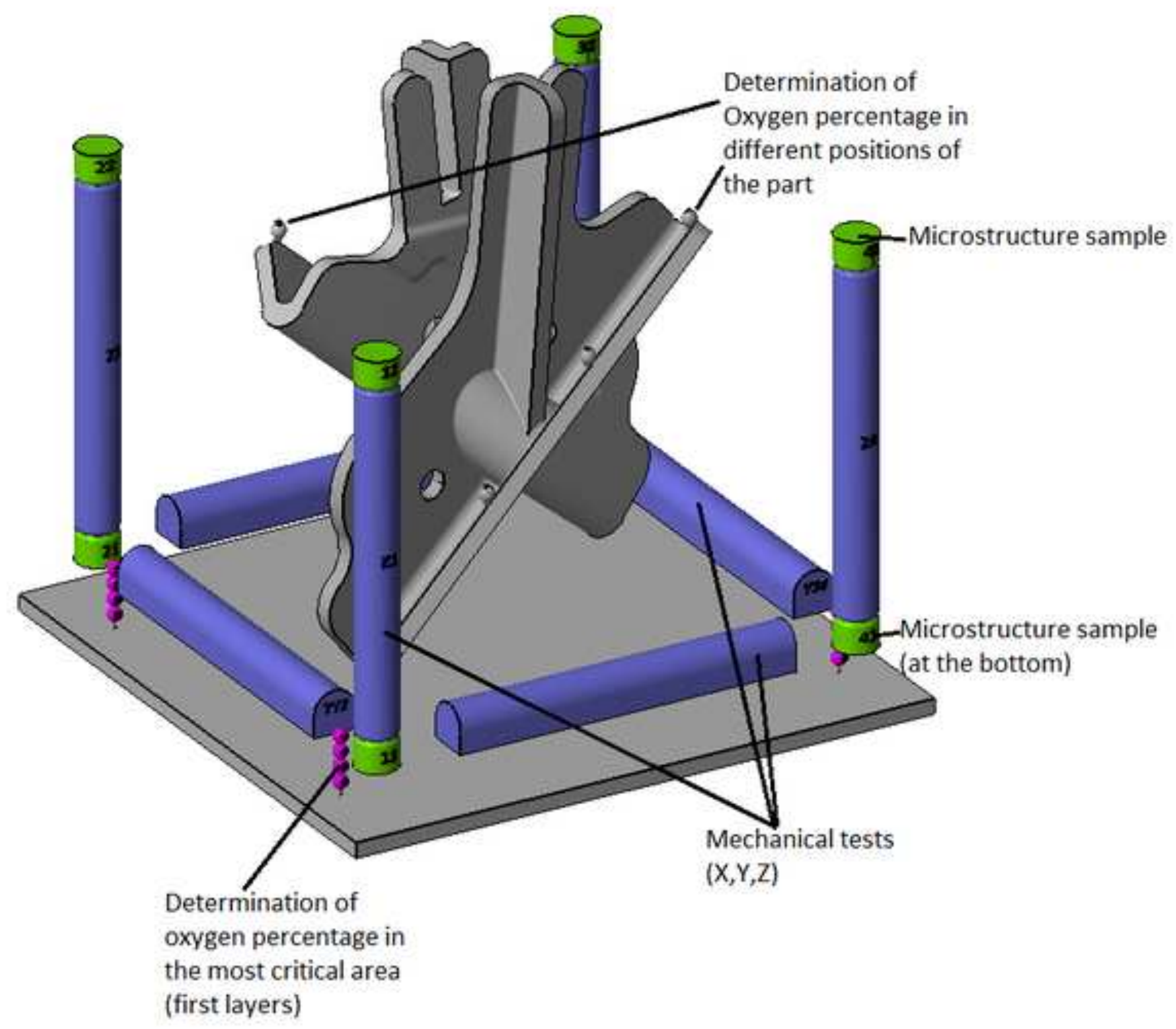


(a) Mechanical properties-Repeatabilitytrend

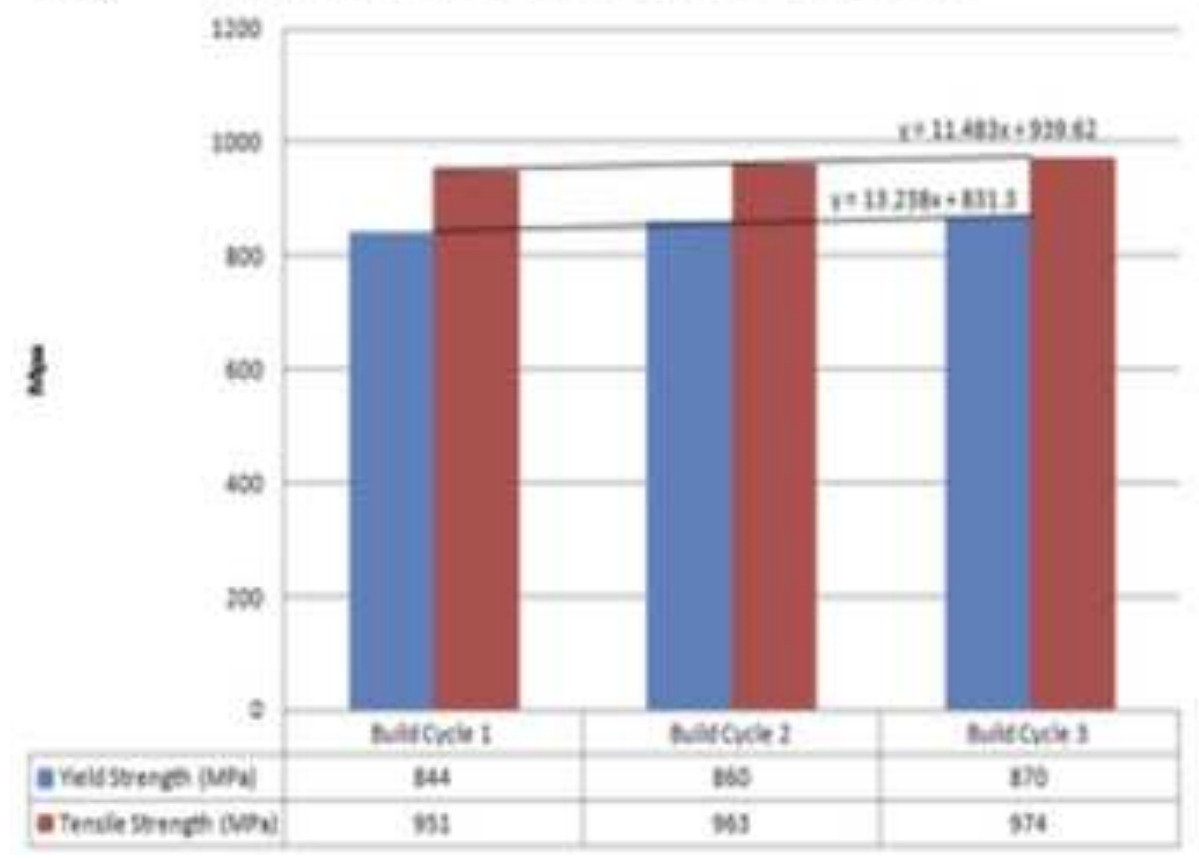

(b)

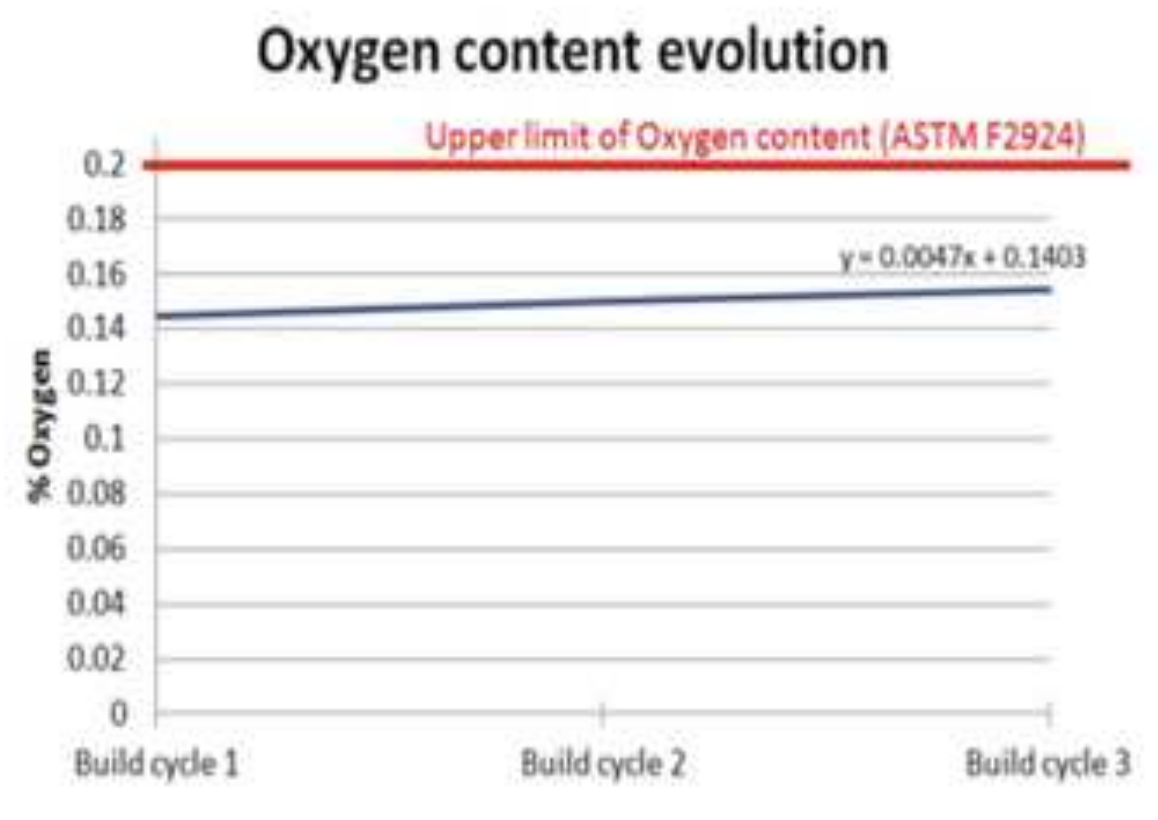

\section{Oxygen content evolution}


LaTeX Source Files
Click here to download LaTeX Source Files: LaTeX_AU_CU.zip

LaTeX Source Files
Click here to download LaTeX Source Files: LaTeX_AU_CU.zip Click here to download LaTeX Source Files: LaTeX AU CU.zip

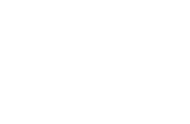

$\sqrt{10}$ (1) (1) (1) $\sqrt{2}$ (1) $\sqrt{2}$ (1) (n) . .

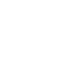

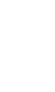
. 更

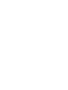

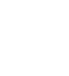

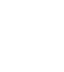

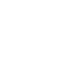

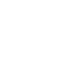

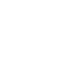

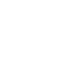

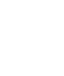

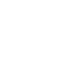

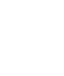

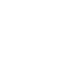

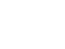




\section{A qualification procedure to manufacture and repair aerospace parts with electron beam melting}

\section{Portoles, L.}

\section{Elsevier}

L. Portolés, O. Jordá, L. Jordá, A. Uriondo, M. Esperon-Miguez, S. Perinpanayagam, A qualification procedure to manufacture and repair aerospace parts with electron beam melting, Journal of Manufacturing Systems, Volume 41, October 2016, pp. 65-75

http://dx.doi.org/10.1016/j.jmsy.2016.07.002.

Downloaded from Cranfield Library Services E-Repository 